\title{
Additive Manufacturing of Thermoplastic M8 Fasteners Using Photopolymer Jetting Technology for Low-Strength Fastening Applications
}

Parth Patpatiya ( $\sim$ paarth.1098@gmail.com )

Banasthali Vidyapith: Banasthali University https://orcid.org/0000-0003-0025-9330

Anshuman Shastri

Banasthali Vidyapith: Banasthali University

\section{Research Article}

Keywords: Photopolymer Jetting, Polyjet, M8 fastener, Vero white, Vero cyan, Vero magenta, Vero grey, Precision

Posted Date: July 30th, 2021

DOl: https://doi.org/10.21203/rs.3.rs-525671/v1

License: (c) (i) This work is licensed under a Creative Commons Attribution 4.0 International License.

Read Full License 


\section{Abstract}

This study investigates the spatial accuracy of additively manufactured M8 fasteners fabricated using photopolymer jetting technology. A number of M8 bolts and their mating M8 nuts are fabricated using Stratasys Object 260 Connex 3 polyjet printer with Vero cyan, Vero magenta, Vero white, and Vero grey thermoplastic resins. Vero series thermo-plastics were used as they offer durability, strength, and flexibility. The additively manufactured nuts and bolts are fabricated with the intention of introducing thermoplastic fasteners that could eventually substitute metal fasteners in certain low strength joining applications such as in fluidics, electronics, biomedical engineering, food packaging, and automobile industries. Manufacturing constraints and critical conditions for fabrication are presented. Vital printing and manufacturing constraints, dimensional stability analysis, and the subsequent dimensional changes for the fabricated fasteners are thoroughly illustrated. Dimensional stability of the printed structures was examined under an ultra-compact 3D laser sensor and the imaging results are also presented. The fabricated thread profile superimposed precisely with the CAD model's ISO thread profile dimensions. The dimensional performance of the fabricated M8 fasteners was examined in every orientation and along each axis of the fasteners. The high-quality manufacturing of fasteners using photopolymer jetting reached the maximum precision requirements and fitted under IT 06 transition fit grade.

\section{Introduction}

3D printing or Additive Manufacturing (AM) [1] is a method of constructing a part by depositing thin layers of the indispensable material one by one. It is amongst the most rapidly rising and high potential manufacturing techniques offering significant advantages over conventional manufacturing techniques [2]. AM unlocks the possibility of paths where the weight factor and the design process method is put in effect with the help of data analyzing approach. A wide range of thermo-plastic materials is available, which have the potential to meet the required industry standards. FIGURE 1 compares additive with subtractive manufacturing. As the complexity of the product geometry increases, AM is proven to be more reliable with fewer inventories, less tooling required and minimal material wastage. With the rapid growth in the reliabilities and mass-production capabilities of the 3D printers, AM of traditional mechanical components such as Bolts, Nuts, Gears, turbine blades, etc., is emerging as a cost-efficient $[3,4]$ manufacturing solution. A variety of advancements in accuracy-based 3D printing have been reported in the last five years [5-10]. Few studies have reported the accuracy issues while fabricating the bolt via AM $[5,10]$. A scale factor is developed for the bolt's fabrication using FDM [5] in which deviations occurred during the printing process that crossed the permissible tolerance limit. The deviations can be evaluated using optimization methods such as the Taguchi method, response surface method (RSM), and Nondominated Sorting Genetic Algorithm (NSGA) [11-13]. A similar trend is perceived while fabricating the bolt via metallic 3D printing using stainless steel, aluminium, and steel [10, 14-16].

A comparison between different methods of 3D printing primarily focusing on mass customization at both prototyping and industry level, is reported in [17-19]. Several manufacturing parameters determine the precision of the fabricated specimens. The printing speed plays a vital role in the 3D printing 
technique for determining the dimensional deviations. Evaluation of the speed and the accuracy of AM machines was reported in [20]. Parameters such as layer thickness and particle size [21, 22], for instance, while fabricating anatomic maxilla and mandible implant guides [21] various processing parameters are examined. Blande Altman analysis and Wilcoxon signed-rank test are performed for checking the mean absolute difference and mean relative difference between SLA and the Polyjet 3D printers. Thermoplastics fasteners such as bolts, screws and gears have become prevalent due to their affordable price, versatility, inability to get corrode, multicolour options, high wear resistance, and fire-resistance. Bolts serve as the backbone of the industries and are commonly used as permanent fasteners in mechanical, civil, and hydraulic developments.

Plastic bolts and nylon fasteners are widely used in various applications [23-30]. Numerous polymer components [23], such as screws, spiky washers, staples, are widely utilised in clinical applications. Orthopaedic screws were manufactured utilising the Fused Deposition Modelling technique [24] to replace metal screws with comparable torsional and compressive strengths. Screws fabricated using PLA (polylactic acid) [25] have a broad range of therapeutic applications. They were utilised to treat a number of people who had developed syndesmosis. Fasteners [26] fabricated using the combination of CF/PEEK are extensively utilised in aircraft constructions owing to their high strength to weight ratio. A similar study discusses a lightweight fibre reinforced thermoplastic rivet [27] that can replace metallic components while joining

them. It is reported to have a stronger joint strength than a metallic riveted joint. Few studies [28, 29] discusses the fabrication standards developed for the additively manufactured thermoplastic components. The experimental investigation [28] was conducted to establish standards for dimensional tolerances for additive manufactured components produced using Fused Deposition Modelling Approach. It is reported that the FDM process achieved tolerances under IT grades between IT09 and IT14 within the specified boundary constraints in accordance with DIN EN ISO 286-1. The accuracy of AM fabricated components using Polyjet, Selective Laser Sintering (SLS), and Fused Deposition Modelling (FDM) techniques [29] was compared. The study establishes the capacity of various printing technology's to replicate thermoplastics components such as polyjet, SLS, and FDM methods. This paper presents a novel fabrication of M8 thermo-plastic fasteners manufactured using photopolymer jetting technology. Numerous M8 bolts and M8 nuts were 3D printed utilizing Vero magenta, Vero cyan, Vero white, and Vero grey thermo-plastic resin. A significant number of studies have investigated the accuracy and strength of metal 3D printing of bolts; however, only a limited number of studies currently exist on thermos-plastic based fasteners using Polyjet based AM [10]. This fabrication method opens new conventions for AM thermos-plastic fasteners, for low strength joining applications. Vero series photopolymer thermoplastic resins offer resilience, stability, chemical and corrosion resistance. Manufacturing constraints along with the critical prefabricating parameters are highlighted while printing the M8 fasteners with the help of a Polyjet printer. The optimal print conditions were identified, and fabrication was carried out in accordance with them. The dimensional inspection of the bolts and nuts is carried out by scanning the fasteners under a high precision 3D scanner. For further analysis the scanned fasteners results are superimposed onto their CAD designed according to ISO 724. The dimensional deviation is examined at three random 
sections of the design to minimize the recorded data uncertainties. Finally, the behaviours of the 3D printed fasteners are compared to validate the printer's capability to reproduce the M8 fasteners.

\section{M8 Bolt And Nut Design}

Table 1

Geometric Parameters of Hexagonal-headed bolt

\begin{tabular}{|llllll|}
\hline $\begin{array}{l}\text { Nominal Diameter } \\
\text { (in mm) }\end{array}$ & M6 & M8 & M10 & M12 & M14 \\
\hline B $\times$ H & $10 \times 4$ & $13 \times 5.5$ & $17 \times 7$ & $19 \times 8$ & $22 \times 9$ \\
\hline Pitch & 1 & 1.25 & 1.5 & 1.75 & 2 \\
\hline
\end{tabular}

Table 2

Geometric Parameters of Hexagonal-headed nut

\begin{tabular}{|llll|}
\hline Nominal Diameter (in mm) & m & s & e \\
\hline M8 & 6.5 & 13 & 15 \\
\hline M10 & 8 & 17 & 19.6 \\
\hline M12 & 10 & 19 & 21.9 \\
\hline
\end{tabular}

Hexagonal-headed fasteners are widely used as mechanical fasteners in a wide range of industrial application. Geometric parameters, such as nominal diameter depth (B), pitch, and length of thread engagement $(H)$, listed in Table 1 and thickness of nut $(m)$, width across flats $(\mathrm{s})$, and height of the nut (e), listed in Table 2, serve as the essential link between design and the manufactured product. Using the standard ISO 724 dimensioning data as depicted in FIGURE 2, an M8 bolt and nut specimens are designed on Computer-Aided Design (CAD) software. The CAD model is then converted into the stereolithography file format (.stl) [32, 33], which stores the information based on CAD models' triangulations.

\subsection{Limits and Fits}

Limits and fits comprise of 18 classes of fundamental tolerances for both shaft and hole designated as IT 01, IT 0, IT 1, and IT 16. They are termed standard tolerances (IS - 919). The following expression is used to calculate the tolerance on a shaft:

$T=k \times i(1)$

Where $\mathrm{T}$ is the tolerance (in micrometres), $\mathrm{K}$ is the constant, and $\mathrm{i}$ is the standard tolerance value (in micrometres) which is obtained by the expression:

$i=0.45^{3} \sqrt{ } D+0.001 D(2)$ 
Where $D$ is defined as:

$$
D=\sqrt{ } D_{1} D_{2}
$$

$\mathrm{D}_{1}$ and $\mathrm{D}_{2}$ (in $\mathrm{mm}$ ) denote the range of maximum and minimum nominal size. The metric threaded bolt is typically fabricated within a narrow tolerance zone. A tolerance zone is a region characterized by the product's upper and lower limit. The amount of deviation and its location with respect to its basic size determine the tolerance zone applied on the thread profile in the permissible range as stated by the International Organisation for Standards (ISO) [34, 35] for manufacturing a fastener. The tolerance zone for a fastener, for instance a bolt and a nut, according to ISO 965, is defined under IT 06 transition fit grade as shown in FIGURE 3, including the standard electroplating tolerances. For instance, a fit between the threaded part is designated as $\mathrm{M} 8 * 1-7 \mathrm{H} / 5 \mathrm{~g} 6 \mathrm{~g}$ specifies that thread has a nominal diameter of 8 $\mathrm{mm}$, pitch $1 \mathrm{~mm}, 7 \mathrm{H}$ tolerance zone for the nut (female mating part), tolerance zone of $5 \mathrm{~g}$ for pitch and 6 $\mathrm{g}$ for the major diameter of the thread. The exact thread profile is crucial for effective thread connections with their mating counterparts. It adversely affects the life and strength of a given threaded joint if the bolt parameters exceed the deviations beyond tolerance limit. As a result, the bolt's geometric parameters' maximum and minimum measurements must be inside the tolerance zone.

\section{Photopolymer Jetting 3d Printing Technology}

Photopolymer jetting or polyjet printing is a method of depositing the material in the form of droplets to create thin layers which are then cured to form 3D components. Photopolymer jetting enables the multimaterial and multicolour printing of polymers. It is commonly used to fabricate complicated geometries, such as cavities, overhangs, undercuts, delicate features, and thin-walled sections. Polyjet printing has a good processing accuracy and can print layers as thin as $16 \mu \mathrm{m}$. Polyjet printing technique [36-38] uses photopolymer materials for building the actual model and requires another gel-like material as a support structure, followed by subsequent curing of the deposited layers. As the supporting materials are soluble and fusible, removing the supports is a simple and damage-free process. Polyjet printer schematic, and the printer can be seen in FIGURE 4 and FIGURE 5, respectively. The bolts were designed using AutoCAD, and their stl files were uploaded to the Stratasys ${ }^{\circledR}$ Object 260 Connex 3 printer. A Water jet gun is typically used to remove the support material (SUP 705) during post-processing. A number of manufacturing considerations and parametric analysis must be taken into account in the manufacturing process using photopolymer jet printers.

\section{Parametric Analysis}

A collection of material properties [36] are available without any recommended printing parameters, so the principle challenge for the designers is to set up the printer and optimize the parameters for the best results as per the design requirements. The impact and interdependencies of the controlling parameters are examined using Design of Experiments (DoE) [38]. A preliminary trial strategy is developed for every 
fabrication run to determine the optimum printing parameters, minimising the dimensional variation. The expression gives the numbers of trials:

$N_{r}=\left[N_{J}\right]_{f}^{N_{f}(4)}$

Where, $N_{r}$ is the Number of trials, $N_{l}$ is the Number of factor levels, and $N_{f}$ is the Number of factors. A total of sixteen tests are performed as depicted in Table 3 (a) for the material Vero grey to evaluate these deviations' effect on the obtained product dimensions [38]. The manufacturing imperfections were overcome using an optimization method that considered the dimensional variation and design analyses. Hence, the minimum, maximum, and mean values are presented in Table 3 (b). Subsequently, the printer and material's optimum conditions as a prerequisite to obtain the printed part's accuracy are outlined in Table 3 (c). For Vero grey, the optimized process parameters obtained using ANOVA

TABLE 3 DESIGN OF EXPERMENTS (A) FABRICATION RUN FOR VERO GREY (B) MAXTMUM, MINMUM AND MEAN PROCESS PARAMETERS VALUES. (C) OPTIMIZED PROCESS PARAMETERS FOR VERO GREY, DIGITAL ABS, RIGLR AND RGD 720. RESPECTIVELY. (D) ANOVA CHART FOR DMENSIONAL DEVLATION (DIMENSIONS IN MM) [38]

\begin{tabular}{lllll}
\hline Pattem & $\begin{array}{l}\text { Surface } \\
\text { finish }\end{array}$ & $\begin{array}{l}\text { Part } \\
\text { crientation }\end{array}$ & $\begin{array}{l}\text { Support } \\
\text { material }\end{array}$ & $\begin{array}{l}\text { Printing } \\
\text { mode }\end{array}$ \\
\hline 1111 & Matte & $0^{\circ}$ & Lite & High Speed \\
\hline 1112 & Matte & $0^{\circ}$ & Lite & High Quality \\
\hline 1121 & Matte & $0^{\circ}$ & Heavy & High Speed \\
\hline 1122 & Matte & $0^{\circ}$ & Heavy & High Quality \\
\hline 1211 & Matte & $90^{\circ}$ & Lite & High Speed \\
\hline 1212 & Matte & $90^{\circ}$ & Lite & High Quality \\
\hline 1221 & Matte & $90^{\circ}$ & Heavy & High Speed \\
\hline 1222 & Matte & $90^{\circ}$ & Heavy & High Quality \\
\hline 2111 & Glossy & $0^{\circ}$ & Lite & High Speed \\
\hline 2112 & Glossy & $0^{\circ}$ & Lite & High Quality \\
\hline 2121 & Glossy & $0^{\circ}$ & Heavy & High Speed \\
\hline 2211 & Olossy & $0^{\circ}$ & Heavy & High Quality \\
\hline 2212 & Glossy & $90^{\circ}$ & Lite & High Speed \\
\hline 2221 & Glossy & $90^{\circ}$ & Lite & High Quality \\
\hline 2222 & Glossy & $90^{\circ}$ & Heavy & High Speed \\
\hline
\end{tabular}

(a)

\begin{tabular}{|c|c|c|c|c|}
\hline & \multicolumn{4}{|c|}{ Verobray } \\
\hline Minimum & 0.18 & .89 .33 & .85 .89 & 2533 \\
\hline Maximum & 3,71 & 162.17 & 3200 & 34,73 \\
\hline Nera & 1.74 & 43.66 & .31 .4 & 30.49 \\
\hline Suodard devizitice & 124 & 8384 & 32.35 & 244 \\
\hline
\end{tabular}

(b)

\begin{tabular}{|c|c|c|c|c|c|}
\hline Material & $\begin{array}{l}\text { Serfice } \\
\text { finis }\end{array}$ & $\begin{array}{l}\text { Prat } \\
\text { crintation }\end{array}$ & $\begin{array}{l}\text { Simper } \\
\text { materid }\end{array}$ & $\begin{array}{l}\text { Theral post- } \\
\text { treument }\end{array}$ & $\begin{array}{l}\text { Priting } \\
\text { mode }\end{array}$ \\
\hline Digits ABS & Gossy & $90^{\circ}$ & Lis & Ire B & 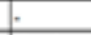 \\
\hline Veocray & Glossy & $900^{\circ}$ & Bewy & - & Hids Spees: \\
\hline $\sin x$ & Glossy & $9 \sigma^{\circ}$ & Line & - & Hith Speet \\
\hline BCD720 & Glossy & $90^{\circ}$ & Late & - & Hith Spees: \\
\hline
\end{tabular}

(c)

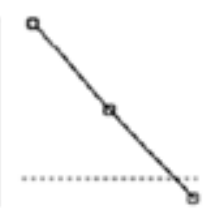

เู่์ ำㅇำ
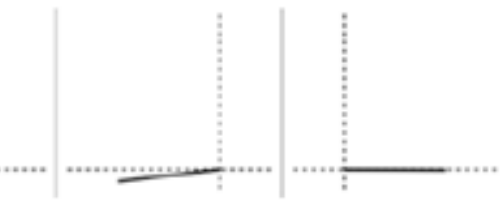

$\stackrel{\$}{3}$
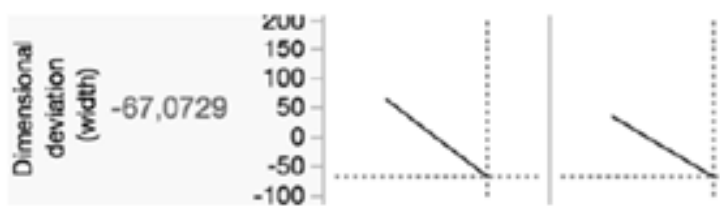

焉苔
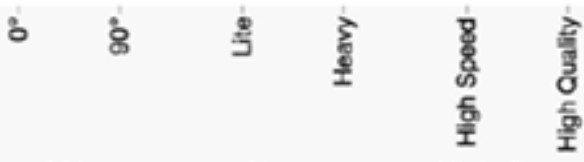

Glossy

Surtace
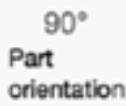

Heavy Support material

High Speed

Printing

mode

Desirability

Table 4 Polyjet Printer's Parameters and the Control Levels

\begin{tabular}{ccc}
\hline Polyjet printer parameters & \multicolumn{2}{c}{ Control Levels } \\
\hline Support Material & Heavy & Lite \\
Print Mode & High Speed & High Quality \\
Print Orientation & $0^{\circ}$ & $90^{\circ}$ \\
Surface Finish & Matte & Glossy \\
\hline
\end{tabular}


technique as depicted in Table 3 (d) [12,40] are glossy surface finish, $90^{\circ}$ orientation of the design, heavy support material and high-speed print condition. These results have served as the optimum match for the print conditions of the M8 bolt using Vero magenta and Vero cyan, respectively, on a photopolymer jetting based 3D printer.

\section{Manufacturing Constraints In Photopolymer Jetting}

Accuracy of the thread profile is an essential parameter for an effective bolt design. Pre-fabrication parameters such as the selection of material, print resolution, turning speed, machine resolution, part size, and machine procurement cost [41-45] are the critical factors in determining the precision of the thread profile. Along with these critical parameters, numerous manufacturing constraints also had to be overcome while fabricating using photopolymer jetting.

First and the foremost, it is critical to identify the print parameters in photopolymer jetting that

affect the critical features of a printed component. Table 4 enlists various printing modes that affect the mechanical properties of the fabricated specimen such as part orientations, support materials, printing speed and surface finish. Therefore, an analysis of the various printer settings is necessary to refine the results in terms of both strength and accuracy. Secondly, the viscosity of the resin is a critical parameter in polyjet printing which requires a low viscosity to ensure easy deposition. A low viscosity resin with a high degree of fluidity reaches the build tray quickly and is suitable for printing high resolution designs [44]. It is essential to have a low-viscosity resin to be injected into the nozzle for a cost-effective solution. Thirdly, producing support-free 3D printing specimens significantly reduces the labour cost. Fourthly, the printing was performed at a $90^{\circ}$ orientation of the design and high-speed mode. This printing mode provides $0.002 \mathrm{~mm}$ resolution of print. It improved the bolt's surface finish and reduced the need for polishing and post-processing. Finally, the products printed using the photo-curing 3D printing methods are porous and have low energy absorption ability. Therefore, material selection restricts the application of the print mode. Vero thermos-plastics offer high fatigue, tensile and torsional strength [36] that ensembles the requirement of any mechanical fastener. The build cabinet of polyjet printer is $870 \mathrm{~mm} \mathrm{X}$ $1200 \mathrm{~mm}$ X $735 \mathrm{~mm}$ in size as demonstrated in FIGURE 6. Parallel printing of bolt samples in various colours was performed to further reduce the printing costs. The material cabinet holding the photopolymer resins measures at $330 \mathrm{~mm} \times 1170 \mathrm{~mm}$ X $640 \mathrm{~mm}$. The optimum operational conditions were maintained at $25^{\circ} \mathrm{C}$ and relative humidity at $60 \%$.

\section{Fabrication}

The fabrication of the M8 fasteners was performed using Stratasys ${ }^{\circledR}$ Object 260 Connex 3 [36]. The process parameters during 3D printing consist of laser power and wavelength that were set to 1.5 kilowatts and 1070 nanometre, respectively. The build time taken to fabricate each bolt was approximately 2 hours and nut was 1.5 hours respectively, and the room temperature was at $25^{\circ} \mathrm{C}$. FIGURE 7 (a) illustrates M8 bolts manufactured using stainless steel and the 3D-printed thermoplastics 
bolts using Vero magenta, Vero cyan and the Vero white photopolymer resin. FIGURE 7 (b) demonstrates the ISO dimensions of a 3D printed bolt. The 3D printed M8 Vero grey nut and partially 3D printed nut demonstrating internal threads are depicted in FIGURE 8 (a) and FIGURE 8 (b) respectively. Along with the M8 nut, a partial M8 nut is 3D printed to scan the internal threads while maintaining the same material and manufacturing conditions as that of the M8 nut. Vero thermos-plastics offer high fatigue, tensile and torsional strength [36] that ensembles the requirement of any mechanical fastener. FIGURE 9 illustrates the three randomly selected regions on the thread profile that are typically located on the bolt's periphery. The specimens were scanned using a Carl Zeiss COMET L3D2 3D scanner [39] as shown in FIGURE 10. The scanning is performed on randomly three selected sections taken on the periphery of the bolt and nut. The 3D scanner is furnished with a superior 3D sensor that utilizes blue LED lighting and 3D inspection. It can amplify the scanning zone without affecting the precision. Further the data acquisition process generated real-time visualization results by superimposing the printed part with the original CAD model in terms of dimensional deviation as shown in FIGURE 11 (a), (b), and (c) respectively. Stratasys Ltd. gives a collection of material properties [36] without recommending any printing parameterization, so the primary challenge for the client is to set up the printer to arrive at the best results regarding their prerequisites towards the printed part. Object 260 Connex 3 printer offers variation in the material's surface finish, part orientation, support material used, and the printing mode [36]. The overall mechanical performance of a bolt is determined by the accuracy of the thread profile and its strength. The mechanical properties of the material must be evaluated before deploying it for any fastening application. A bolt is typically subjected to tensile, shear and torsion loads. The tensile strength is the highest tension load that a fastener will withstand until failing whereas flexural strength is concerned about the material's susceptibility to deformation. Failure typically occurs due to combination of forces that causes cracking. The mechanical properties of Vero cyan Vero magenta, Vero white and Vero grey are depicted in Table 5. It can be noted that Vero thermoplastics fulfil a wide range of design criteria resilience, stability, chemical and corrosion resistant, as well as being lightweight.

\section{Results And Analysis}

The influence of printing conditions is observed on the average deviation values of the fasteners fabricated with the help of Polyjet Technology. Fasteners were printed at the optimum condition for the printer that were glossy surface finish, heavy support material, $90^{\circ}$-part orientation, high-speed printing, and $25^{\circ} \mathrm{C}$ ambient temperature. The study compares pitch, depth of thread, thread angle, and thread engagement of the M8 bolt with the standard values.

\subsection{Thread Profile Analysis for bolt}

Threads are the grooves of a uniform section cut on the internal or external surface of a cylinder in the shape of a helix. The bolt's strength is incredibly reliant on the thread 
Table 5

The Mechanical Properties of Vero Magenta, Cyan, White, and Grey

[36]

\begin{tabular}{|ll|}
\hline Mechanical Properties & Vero Magenta / Cyan \\
\hline Tensile Strength & $50-65$ Mega Pascal (D-638-03) \\
\hline Elongation at Break & $10-25 \%$ (D-638-05) \\
\hline Modulus of Elasticity & $2,000-3,000$ Mega Pascal (D-638-04) \\
\hline Flexural Strength & $75-110$ Mega Pascal (D-790-03) \\
\hline Flexural Modulus & $2,200-3,200 \mathrm{MPa}(\mathrm{D}-790-04)$ \\
\hline Heat Deflection & $45-50^{\circ} \mathrm{C}(\mathrm{D}-648-06)$ \\
\hline Temperature @ 0.45MPa & \\
\hline Shore Hardness (D) & Scale D 83-86 \\
\hline
\end{tabular}

profile. The average observations are presented in FIGURE 12-15. Three regions of the bolt, namely, the greater end, the centre region, and the lower end, are thoroughly observed. Thread angle is defined as the included angle between flanks of the bolt. FIGURE 12 depicts a deviation of approximately $4^{0}$ in the thread angle for mild steel M8 bolt when measured with a 3D scanner. A deviation of $4.469^{\circ}$ and $3.278^{\circ}$ is observed for Vero cyan Vero magenta, respectively, as shown in FIGURE 13 and FIGURE 14, respectively. Pitch refers to the space between two consecutive threads. The maximum deviation is observed for the radial distance between root and crest and the minimum deviation for pitch. The depth of thread is the difference between successive bases in a plane normal to the axes. While measuring the depth of thread, a deviation of $0.176 \mathrm{~mm}$ for Vero cyan and $0.21 \mathrm{~mm}$ for Vero magenta is detected. FIGURE 15 illustrates the thread profile of a Vero white bolt. The thread angle in the thread profile deviates by a maximum of $2.5^{\circ}$, while length of thread engagement deviates by a minimum of $0.8 \mathrm{~mm}$.

\subsection{Thread Profile Analysis for nut}

A nut is the female counterpart of the bolt [46], consists mainly of a square or hexagonal head with a bore in the middle region along with the internal threads that engage the male threads of the bolt. During effective bolt installation, a nut assists in fastening the component along the bolt's axis. The coefficient of friction between mating threads has a significant impact on the force generated to fasten the component. The threads on the nut are identical to those on the mating bolt. The strength of the bolt is extremely dependent on the mating nut's thread profile. A thread angle variation of about $3{ }^{\circ}$ for Vero grey nut is observed when compared to ISO standard values as illustrated in FIGURE 16 (a). As shown in FIGURE 16 (b), surface characteristics such as length and width are measured for a completely printed Vero grey nut. A deviation of $0.7 \mathrm{~mm}$ for depth of thread and $0.05 \mathrm{~mm}$ for length of thread engagement, respectively was observed for Vero grey nut. The mean observations are discussed in FIGURE 17 which compares the pitch, thread angle, depth, and length of thread engagement of Vero cyan bolt, Vero 
magenta bolt, Vero white bolt, and Vero grey nut with the stainless steel M8 bolt and the ISO dimensions. It can be noted that for Vero grey nuts, the maximum deviation occurs at the thread angle of $3^{\circ}$, while the smallest discrepancy occurs at the pitch of $0.01 \mathrm{~mm}$. The pitch, depth of the thread, and the thread engagement length demonstrate maximum deviation for Vero magenta by $0.06 \mathrm{~mm}, 0.21 \mathrm{~mm}$, and 0.115 $\mathrm{mm}$, respectively.

The highest discrepancies are observed for the Vero magenta M8 bolt, whereas the lowest is observed for the Vero cyan M8 bolt.

\section{3. $3 \mathrm{D}$ Inspection of the bolt}

3D scanning is a technique of inspecting precise details of the component. Carl Zeiss COMET L3D2 3D scanner [39] as shown in FIGURE 10 was used to analyse the fastener's geometric features and compared the gathered dimensions with the ISO standards. Sixteen points are inspected on the printed bolt's geometric features, and results are averaged in terms of dimensional deviation. The $X, Y$ and $Z$ coordinates are captured using ZEISS colin3D software. Nominal value, actual value and the deviations between the captured and ISO dimensions are presented in FIGURE 18-20. Points are arbitrarily taken in these regions on the periphery of the 3D printed Vero cyan, Vero magenta, and Vero white bolts.

The positive values indicate a larger dimension than the standard value whereas the negative values indicate a smaller dimension than the standard value. These points function as the reference parameters for evaluating the directional deviation. The directional deviations and total deviation values are calculated, and the dimensional inspection is performed along $X, Y$, and $Z$ directions. The origin is kept at the bolt's centre for measuring the displacement field, and horizontal and vertical directions are assumed as the positive $X$ and $Y$-axis, respectively. FIGURE 18 illustrates the deviation trend for the Vero white bolt. The green zone of the tolerance chart indicates that there is little variation than the red zone. The deviations are more towards the lower end of the Vero white bolt. FIGURE 19 depicts that the 3D printed Vero cyan bolts profile slightly deviates from the roots and peaks of the ISO M8 bolt. The major portions of the peaks and roots are missed by Vero magenta. The thread failure of the bolt occurs due to combination of tensile, compressive, shear and torsional stresses. The crack initiates at the thread root and grows until the failure of the bolt. Maximum load is carried by the roots and peaks of the thread. Dimensional deviations, is therefore, the main concern which determines the effective bolt connection. Directional deviations for Vero white, Vero cyan, and Vero magenta M8 bolts are calculated and shown in FIGURE 21 (a), (b), and (c), respectively. The strength of the bolted connection majorly depends on the accuracy of thread profile. FIGURES 22-24 depict a two-dimensional sectional view of the thread profile, highlighting the superimposed peaks and roots of the 3D printed bolt on the ISO-compliant M8 bolt. The deviations in the roots and peeks are more towards the lower end of the bolt.

\section{4. $3 \mathrm{D}$ Inspection of the nut}

The "fit" is the dimensional clearance between two mating components, and its magnitude affects the mating components' ability to slide and revolve independently. M8 nuts are fabricated with in the IT 06 transition fit grade to determine the tolerance zone for the mating bolt and nut. The mating M8 nut is 
additively manufactured using Vero grey thermoplastic and fabricated under the similar printing conditions. Internal thread quality is determined using a half3D printed nut, while geometric morphology is determined using a full 3D printed nut. The Carl Zeiss COMET L3D2 3D scanner is used to scan the additively manufactured Vero grey nut [37]. FIGURE 25 illustrates a three-dimensional tolerance chart showing the deviation for the nut. The thread tolerance chart governs the transmission accuracy of the mating parts. The greatest deviation occurs near the nut's top surface, as shown by the red zone on its thread profile while the smallest deviation occurs towards the nut's threads. The major peaks and crests are missed near the base of the nut. The thread defects among the mating parts initiates failure in the threaded joint. Directional deviations for Vero grey M8 nut are calculated and shown in Fig. 26.

It is perceived that the directional deviations become more prominent as we move towards the lower end of the bolt. They are more along Y-axis for Vero cyan, Vero white bolt and more along the Z-axis for Vero magenta bolt. In case of Vero grey nut the deflection along the $Y$-axis is more significant. The maximum deviation is $\pm 0.09 \mathrm{~mm}$ in case of cyan bolt, $\pm 0.12 \mathrm{~mm}$ in case of magenta bolt and $0.14 \mathrm{~mm}$ in case of Vero white bolt. For the Vero grey nut the maximum deflection is $\pm 0.1 \mathrm{~mm}$ along the $Y$-axis. Standard deviation for Vero white bolt is higher than Vero cyan and Vero magenta bolts, which can be seen from the scanned data set since the values are unevenly located from the actual values. The standard deviation of Vero grey nuts is lower than that of additively manufactured bolts, since the deviations from the ISO standard values are less scattered.

Finally, Table 6 presents a comparative analysis between various fabrication methods such as photopolymer jetting, SLA, FDM, MJF, MJP, and SLS on the basis of their dimensional accuracies. A range of printing materials such as PLA, ABS, Polyamide12, clear resin, epoxy resin and Vero photopolymer are employed and various printing parameters are presented and compared in terms of their dimensional precision in the fabrication of the manufactured components.SLA reported the highest accuracy of \pm 0.05 $\mathrm{mm}$ whereas polyamide 12 demonstrated the lowest accuracy of all the presented materials at \pm 1.136 $\mathrm{mm}$. An accuracy of $\pm 0.12 \mathrm{~mm}$ is reported with the fabrication of the presented M8 bolts using Vero magenta colour whereas the accuracy was as low as $\pm 0.1 \mathrm{~mm}$ for Vero cyan. It is observed to be more accurate than FDM $[6,11,20]$, SLA $[13,21]$. 


\section{Table 6}

Overview of various AM Printing Techniques, 3D Printing Materials, Process Parameters and Fabricated Design Accuracies.

\begin{tabular}{|c|c|c|c|c|}
\hline Ref. No. & $\begin{array}{l}\text { Printing } \\
\text { Technique }\end{array}$ & Printing Material & Process Parameters & Dimensional Accuracy \\
\hline [5] & - FDM & $\begin{array}{l}-\mathrm{ABS} \\
-\mathrm{PLA}\end{array}$ & - Thread Accuracy & $\begin{array}{l}-\quad \text { Deviation of } \pm 0.13 \\
\text { mm. }\end{array}$ \\
\hline [6] & $\begin{array}{ll}- & \text { SLS } \\
- & \text { FDM }\end{array}$ & $\begin{array}{ll}- & \text { PA6 } \\
- & \text { PA66 }\end{array}$ & $\begin{array}{l}\text { - Multi-functionality of 3D } \\
\text { printing. } \\
\text { - Quality of the } \\
\text { components. } \\
\text { Strength of the product. }\end{array}$ & Accuracy of $9 \%$ \\
\hline [11] & - FDM & - PLA & $\begin{array}{l}\text { - Dimensional deviations } \\
\text { - } \quad \text { Surface roughness }\end{array}$ & $\begin{array}{l}\text { Deviation of } \pm 0.75 \\
\mathrm{~mm}\end{array}$ \\
\hline [13] & $-\quad$ SLA & - Epoxy resin & $\begin{array}{lc}- & \text { Dimensional deviations } \\
- & \text { Surface roughness }\end{array}$ & $\begin{array}{l}\text { Accuracy of } \pm 0.13 \\
\text { mm. }\end{array}$ \\
\hline [20] & $\begin{array}{ll}- & \text { Polyjet } \\
- & \text { SLS } \\
- & \text { FDM } \\
- & \text { Laser } \\
& \text { Sintering }\end{array}$ & $\begin{array}{l}\text { - ABS } \\
\text { - PLA }\end{array}$ & $\begin{array}{ll}\text { - } & \text { Average fabricating } \\
\text { speed. } \\
\text { - } \quad \text { Printing accuracy } \\
\text { - } \quad \text { Structure, properties and } \\
\text { testing of AM machines. }\end{array}$ & $\begin{array}{l}\text { SLA reports the } \\
\text { highest accuracy of } \\
\pm 0.05 \mathrm{~mm} .\end{array}$ \\
\hline [21] & $\begin{array}{ll}- & \text { Polyjet } \\
- & \text { MJP } \\
- & \text { SLA }\end{array}$ & $\begin{array}{l}\text { - Yisijet crystal } \\
\text { - Clear resin } \\
\text { - Vero Magenta }\end{array}$ & _ $\quad$ Printing accuracy & $\begin{array}{l}\text { - Polyjet reports the } \\
\text { highest accuracy of } \\
\pm 0.06 \mathrm{~mm} \text {. }\end{array}$ \\
\hline $\begin{array}{l}\text { Proposed } \\
\text { designs }\end{array}$ & - Polyjet & $\begin{array}{l}-\quad \text { Vero cyan } \\
-\quad \text { Vero magenta } \\
-\quad \text { Vero white } \\
-\quad \text { Vero grey }\end{array}$ & _ Dimensional deviation & $\begin{array}{l}\text { Accuracy of } \pm 0.12 \\
\mathrm{~mm} .\end{array}$ \\
\hline
\end{tabular}

\section{Conclusion}

The AM of thermoplastic M8 fasteners using photopolymer jetting technology was presented with the aim of introducing thermoplastic fasteners which are specifically designed for low strength joining applications. The dimensional performance of a number of M8 fasteners fabricated using photopolymer jetting technology was examined. The M8 bolts and nuts were fabricated using the Stratasys Object 260 Connex 3 polyjet printer utilizing Vero cyan, Vero magenta, Vero white, and Vero grey thermoplastics resin. Lightweight Vero thermoplastics exhibit a wide range of essential thermomechanical properties such as hardness, brittleness, and toughness. Various critical fabrication constraints such as the polyjet printer's general printing limits and critical pre-fabrication parameters, were comprehensively addressed. The optimum print conditions were determined using the ANOVA parametric study method to minimise the dimensional deviation of the fabricated parts. The geometric parameters of the 3D printed fasteners were superimposed with the ISO standard parameters. The 3D scanning observations for Vero cyan, Vero magenta, Vero white, and Vero grey scanned M8 bolt and nut samples were analysed using a Carl Zeiss COMET L3D2 3D scanner. After dimensionally inspecting the pitch, depth of thread and the length of the thread engagement for both the mating components, it was established that the effective thread connections fabricated using photopolymer jetting are possible in the IT 06 transition fit. It was observed that the minimal error was obtained for the pitch value, and the maximum error was obtained for the 
depth of thread for Vero magenta bolt. The superimposition of the 3D printed fastener's thread profile over the ISO-compliant CAD thread profile demonstrated that Vero thermoplastics fasteners perfectly overlap the majority of the crests and roots. The peaks and valleys of the mating nut's internal threads align perfectly with the Vero thermoplastic bolt. Vero series thermoplastics showed an overall deviation of $0.12 \mathrm{~mm}$ while fabricating M8 fasteners. Under the same fabrication circumstances, thread engagement is achievable for all fasteners produced with polyjet technology. The maximum deviation for the M8 bolts and M8 nut lies inside the $6 \mathrm{~g}$ tolerance band. Therefore, photopolymer jetting as a method could be significantly desirable since it did not require any scaling factor in the fabrication of most designs before their fabrication. This study can help professionals and software developers in producing varying models and relationship in the field of AM.

Plastic fasteners can serve as an excellent alternative for metal fasteners, particularly in various low strength applications. Most commonly used plastic fasteners are screws, washers, nuts, gears, and bearings. This investigation into the manufacturing constraints could play a vital role in developing the guidelines for the fabrication of bolts using techniques such as photopolymer jetting. Measurement results may vary from machine to machine, but the deviation patterns and trends for the photopolymer jetting method, in general, tend to be similar. Products that require definite dimensions in the tolerance zone can be fabricated using photopolymer jetting technology with Vero series thermoplastic. AM can also be utilized in the production of other bolts printed with their actual dimensions. Further studies can be conducted along the lines in the manufacturing constraints and stability analysis of other fasteners such as M6 and M12 bolts, gears, washers, and nuts.

\section{Declarations}

\section{Conflict of Interest}

The authors have no conflicts of interest to declare that are relevant to the content of this article.

\section{Funding}

The authors did not receive support from any organization for the submitted work.

\section{Availability of Data and Material}

There is no conflict over the availability of the data and material for this submitted work.

\section{Code availability}

NA

\section{References}


1. Vaneker T, Bernard A, Moroni G et al (2020) Design for additive manufacturing: Framework and methodology. CIRP Ann 69:578-599. doi:10.1016/j.cirp.2020.05.006

2. Calignano F, Manfredi D, Ambrosio EP et al (2017) Overview on Additive Manufacturing Technologies. Proceedings of the IEEE 105:593-612. doi: 10.1109/jproc.2016.2625098

3. Bourell DL, Rosen DW, Leu MC (2014) The Roadmap for Additive Manufacturing and Its Impact. 3D Printing and Additive Manufacturing 1:6-9. doi: 10.1089/3dp.2013.0002

4. In: Wohlers Associates. http://www.wohlersassociates.com/2016report.htm. Accessed 29 Apr 2021

5. Tronvoll SA, Elverum CW, Welo T (2018) Dimensional accuracy of threads manufactured by fused deposition modeling. Procedia Manufacturing 26:763-773. doi:10.1016/j.promfg.2018.07.088

6. Noriega A, Blanco D, Alvarez BJ, Garcia A (2013) Dimensional accuracy improvement of FDM square cross-section parts using artificial neural networks and an optimization algorithm. The International Journal of Advanced Manufacturing Technology 69:2301-2313. doi:10.1007/s00170-013-5196-2

7. Equbal A, Sood AK, Mahapatra SS (2011) Prediction of dimensional accuracy in fused deposition modelling: a fuzzy logic approach. International Journal of Productivity Quality Management 7:22. doi:10.1504/ijpqm.2011.037730

8. Abeykoon C, Sri-Amphorn P, Fernando A (2020) Optimization of fused deposition modeling parameters for improved PLA and ABS 3D printed structures. International Journal of Lightweight Materials Manufacture 3:284-297. doi:10.1016/j.ijlmm.2020.03.003

9. Ituarte IF, Boddeti N, Hassani V et al (2019) Design and additive manufacture of functionally graded structures based on digital materials. Additive Manufacturing 30:100839.

doi:10.1016/j.addma.2019.100839

10. Feng $X$, Xue $F$ (2020) Characterization of 3D printed bolts based on digital image correlation and infrared thermography. Materials Design 191:108641. doi:10.1016/j.matdes.2020.108641

11. Dantan J-Y, Huang Z, Goka E et al (2017) Geometrical variations management for additive manufactured product. CIRP Ann 66:161-164. doi:10.1016/j.cirp.2017.04.034

12. Shen H, Guo S, Fu J, Lin Z (2020) Building Orientation Determination Based on Multi-Objective Optimization for Additive Manufacturing. 3D Printing and Additive Manufacturing 7:186-197. doi: 10.1089/3dp.2019.0106

13. Zhou JG, Herscovici D, Chen CC (2000) Parametric process optimization to improve the accuracy of rapid prototyped stereolithography parts. Int J Mach Tools Manuf 40:363-379. doi:10.1016/s08906955(99)00068-1

14. Kong D, Ni X, Dong C et al (2018) Bio-functional and anti-corrosive 3D printing 316L stainless steel fabricated by selective laser melting. Materials Design 152:88-101. doi:10.1016/j.matdes.2018.04.058

15. Strauss J. Additive Manufacturing of Precious Metals. Additive Manufacturing Processes. 2020; 419-27. 
16. Aboulkhair NT, Simonelli M, Parry L et al (2019) 3D printing of Aluminium alloys: Additive Manufacturing of Aluminium alloys using selective laser melting. Prog Mater Sci 106:100578. doi:10.1016/j.pmatsci.2019.100578

17. Weller C, Kleer R, Piller FT (2015) Economic implications of 3D printing: Market structure models in light of additive manufacturing revisited. Int J Prod Econ 164:43-56. doi:10.1016/j.jpe.2015.02.020

18. Berman B (2012) 3-D printing: The new industrial revolution. Bus Horiz 55:155-162. doi:10.1016/j.bushor.2011.11.003

19. AbuElmagd I, Shabaan A, Salah eldin A (2017) Accuracy of Flapless implant placement with 3D printed surgical guide. Egyptian Dental Journal 63:2225-2233. doi:10.21608/edj.2017.75754

20. Brajlih T, Valentan B, Balic J, Drstvensek I (2011) Speed and accuracy evaluation of additive manufacturing machines. Rapid Prototyping Journal 17:64-75. doi:10.1108/13552541111098644

21. Kim T, Lee S, Kim GB et al (2020) Accuracy of a simplified 3D-printed implant surgical guide. The Journal of Prosthetic Dentistry. doi:10.1016/j.prosdent.2019.06.006

22. McLouth TD, Severino JV, Adams PM et al (2017) The impact of print orientation and raster pattern on fracture toughness in additively manufactured ABS. Additive Manufacturing 18:103-109. doi:10.1016/j.addma.2017.09.003

23. Ramos DM, Dhandapani R, Subramanian A et al (2020) Clinical complications of biodegradable screws for ligament injuries. Materials Science Engineering: C 109:110423.

doi:10.1016/j.msec.2019.110423

24. Dhandapani R, Krishnan PD, Zennifer A et al (2020) Additive manufacturing of biodegradable porous orthopaedic screw. Bioactive Materials 5:458-467. doi:10.1016/j.bioactmat.2020.03.009

25. Cox S, Mukherjee DP, Ogden AL et al (2005) Distal tibiofibular syndesmosis fixation: A cadaveric, simulated fracture stabilization study comparing bioabsorbable and metallic single screw fixation. The Journal of Foot Ankle Surgery 44:144-151. doi:10.1053/j.jfas.2005.01.010

26. Yao C, Qi Z, Chen W, Zhang C (2021) Experimental study on CF/PEEK thermoplastic fastener: Effects of fastener matrix crystallinity and fibre content on the strength of single-lap joint. Composites Part B: Engineering 213:108737. doi:10.1016/j.compositesb.2021.108737

27. Ueda M, Ui N, Ohtani A (2018) Lightweight and anti-corrosive fiber reinforced thermoplastic rivet. Compos Struct 188:356-362. doi:10.1016/j.compstruct.2018.01.040

28. Lieneke T, Denzer V, Adam GAO, Zimmer D (2016) Dimensional Tolerances for Additive Manufacturing: Experimental Investigation for Fused Deposition Modeling. Procedia CIRP 43:286291. doi:10.1016/j.procir.2016.02.361

29. Ibrahim D, Broilo TL, Heitz C et al (2009) Dimensional error of selective laser sintering, threedimensional printing and PolyJet ${ }^{\mathrm{TM}}$ models in the reproduction of mandibular anatomy. Journal of Cranio-Maxillofacial Surgery 37:167-173. doi:10.1016/j.jcms.2008.10.008

30. Rosato DV, Rosato DV, RosatoMV (2004) 11 - casting. In: Rosato DV, Rosato DV, Rosato MV (eds) Plastic product material and process selection handbook. Elsevier, Oxford, pp 394-405. https://doi.org/10.1016/B978-185617431-2/50014-1 
31. Singh R (2011) Process capability study of polyjet printing for plastic components. J Mech Sci Technol 25:1011-1015. doi:10.1007/s12206-011-0203-8

32. Gaynor AT, Johnson TE (2020) Eliminating occluded voids in additive manufacturing design via a projection-based topology optimization scheme. Additive Manufacturing 33:101149. doi:10.1016/j.addma.2020.101149

33. Patpatiya P, Sharma S, Bhatnagar V et al. Approaches for Concising AutoCAD Files. Proceedings of International Conference on Advancements in Computing and Management (ICACM). 2019

34. Kreisköther K, Kampker A, Reinders C (2017) Material and parameter analysis of the polyjet process for mold making using design of experiments. World Journal of Nuclear Science Technology 11:3116

35. ZEISS Optotechnik COMET L3D review - 3D scanner. In: Aniwaa. https://www.aniwaa.com/product/3d-scanners/zeiss-optotechnik-comet-I3d/. Accessed 29 Apr 2021

36. https://standards.nasa.gov/sites/default/files/nasa-std-5020a.pdf

37. https://. Accessed 29 Apr 2021

38. Cathelin J, Sedighiamiri A (2014) Advanced material solutions for plastic gear. International Gear Conference 2014: 26th-28th August 2014, Lyon 1179-1183. doi: 10.1533/9781782421955.1179

39. Connex3 Objet260 3D Printer for Multi-color Multi-material Models. In: Stratasys. https://www.stratasys.com/3d-printers/objet260-connex3. Accessed 29 Apr 2021

40. . Yap YL, Wang C, Sing SL et al (2017) Material jetting additive manufacturing: An experimental study using designed metrological benchmarks. Precis Eng 50:275-285. doi:10.1016/j.precisioneng.2017.05.015

41. Bandyopadhyay A, Heer B (2018) Additive manufacturing of multi-material structures. Materials Science Engineering: R: Reports 129:1-16. doi:10.1016/j.mser.2018.04.001

42. Hassanifard S, Hashemi SM (2020) On the strain-life fatigue parameters of additive manufactured plastic materials through fused filament fabrication process. Additive Manufacturing 32:100973. doi:10.1016/j.addma.2019.100973

43. Vdovin R, Tomilina T, Smelov V, Laktionova M (2017) Implementation of the Additive PolyJet Technology to the Development and Fabricating the Samples of the Acoustic Metamaterials. Procedia Eng 176:595-599. doi:10.1016/j.proeng.2017.02.302

44. Quan H, Zhang T, Xu H et al (2020) Photo-curing 3D printing technique and its challenges. Bioactive Materials 5:110-115. doi:10.1016/j.bioactmat.2019.12.003

45. Somireddy M, Czekanski A (2020) Anisotropic material behavior of 3D printed composite structures - Material extrusion additive manufacturing. Materials Design 195:108953. doi:10.1016/j.matdes.2020.108953

46. Lumley R (2011) Fundamentals of aluminium metallurgy: production, processing and applications. Woodhead, Oxford 
Figures
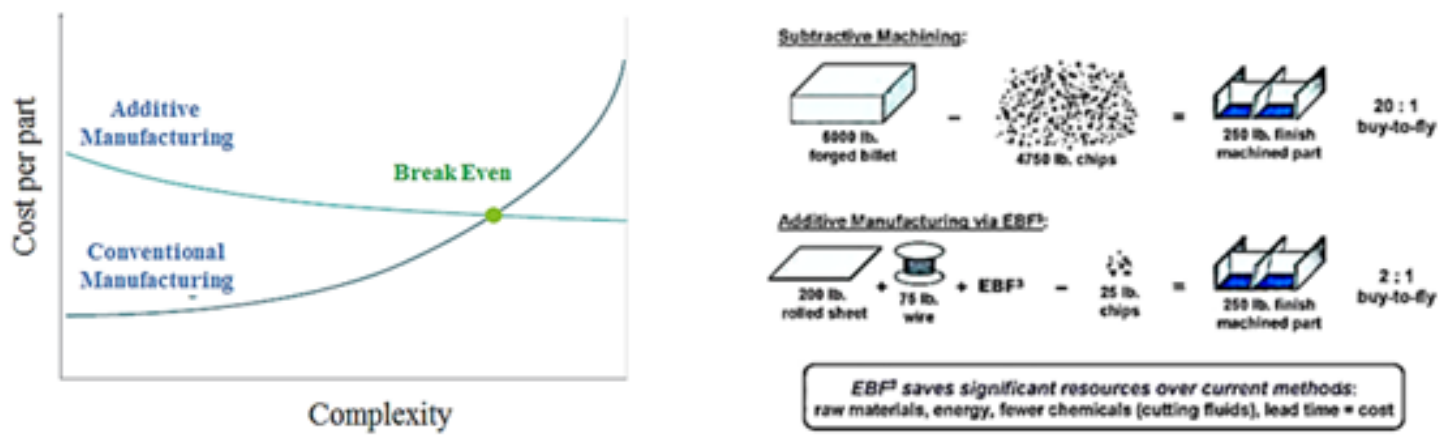

Figure 1

Additive manufacturing vs Subtractive Manufacturing $[3,4]$
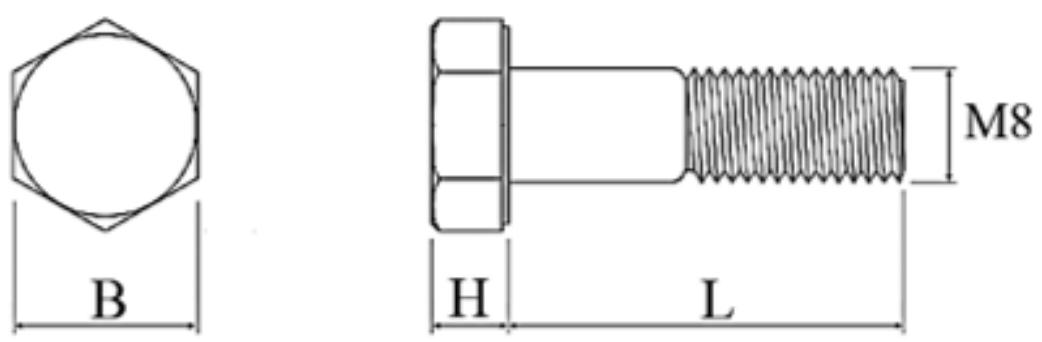

(a)
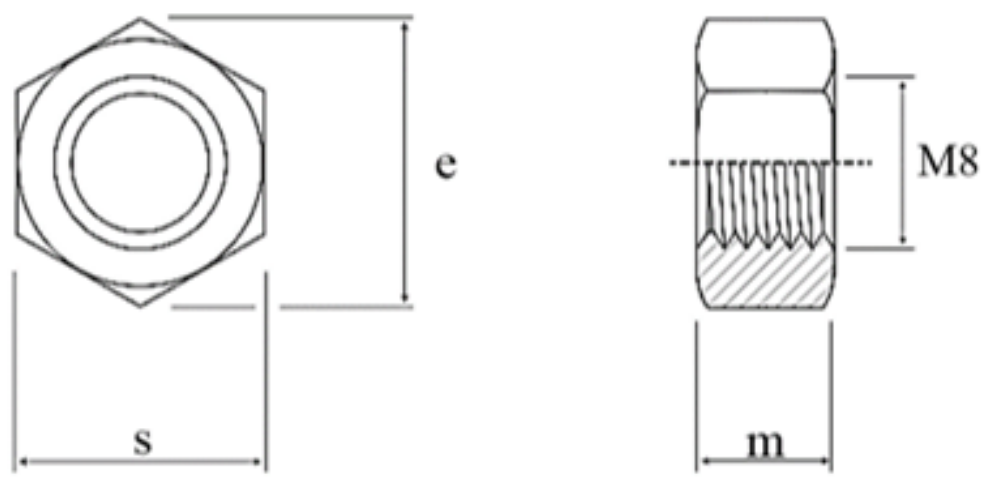

(b)

Figure 2

(a). The schematic of Hexagonal headed bolt. (b) The schematic of Hexagonal headed M8 nut 


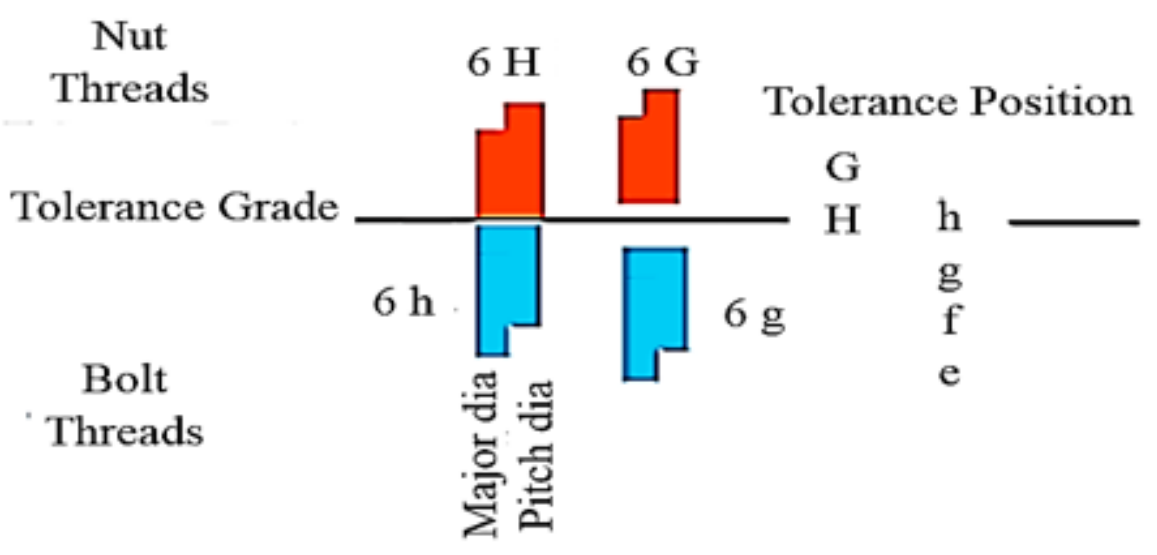

\section{Figure 3}

Fit and tolerances of bolts and nuts according to ISO 724 .

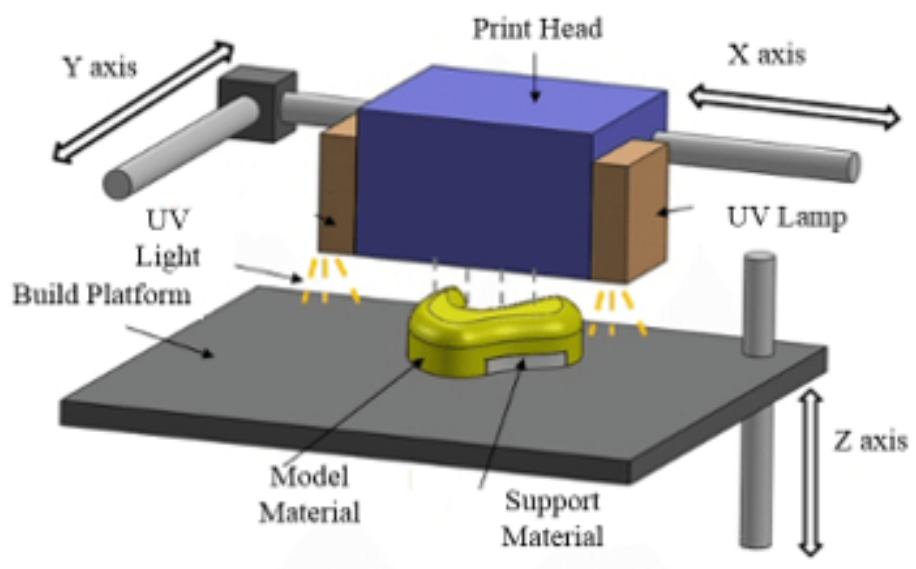

Figure 4

Schematic of Polyjet printer

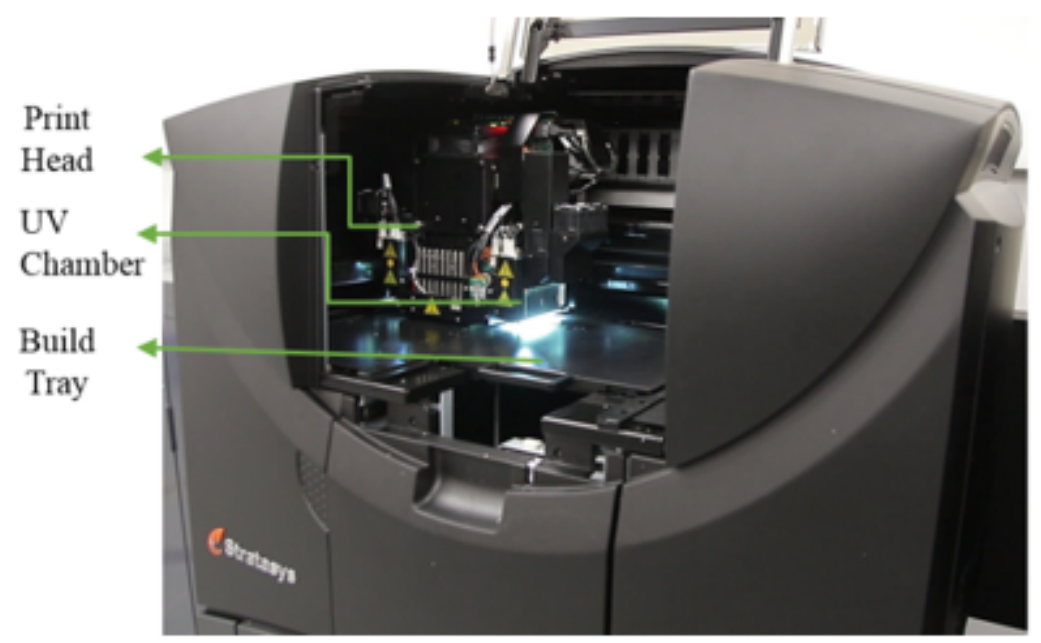


Figure 5

Stratasys Object 260 Connex 3 Polyjet 3D printer

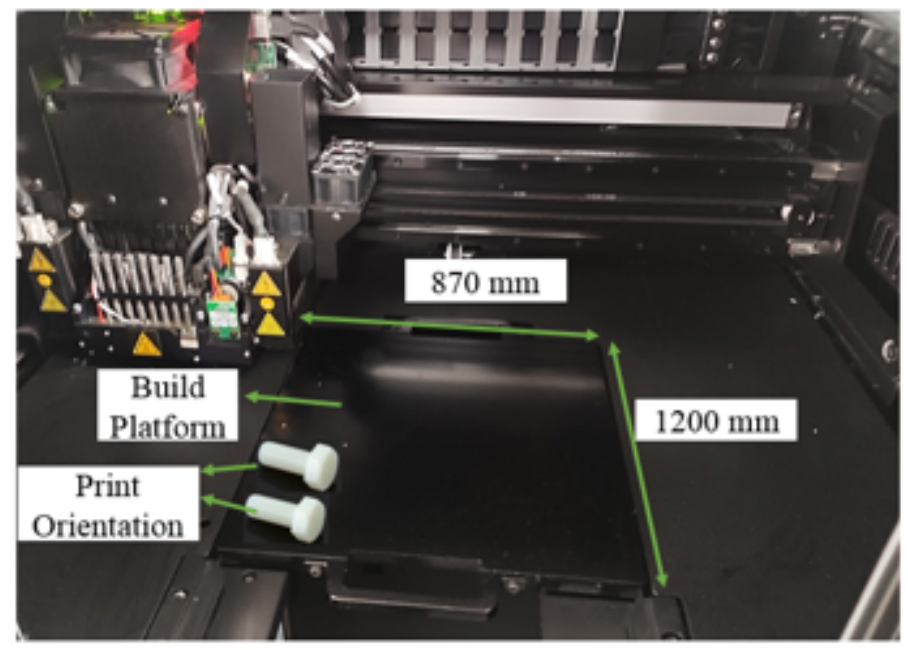

Figure 6

Build cabinet of Stratasys Object 260 Connex 3. 
Stainless Steel

M8 Bolt

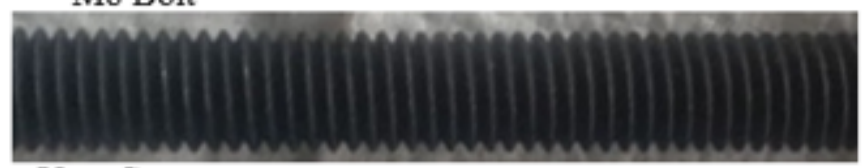

Vero Cyan

M8 Bolt

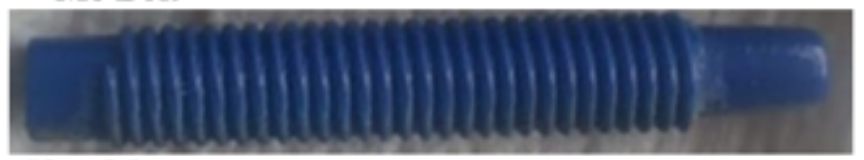

Vero Magenta

M8 Bolt

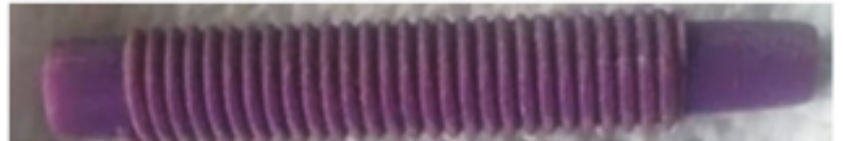

Vero White

M8 Bolt

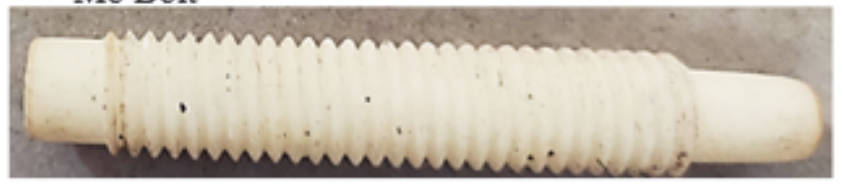

FIGURE 7 (a). M8 Stainless Steel with M8 Vero magenta, M8

Vero cyan and M8 Vero white 3D printed bolts.
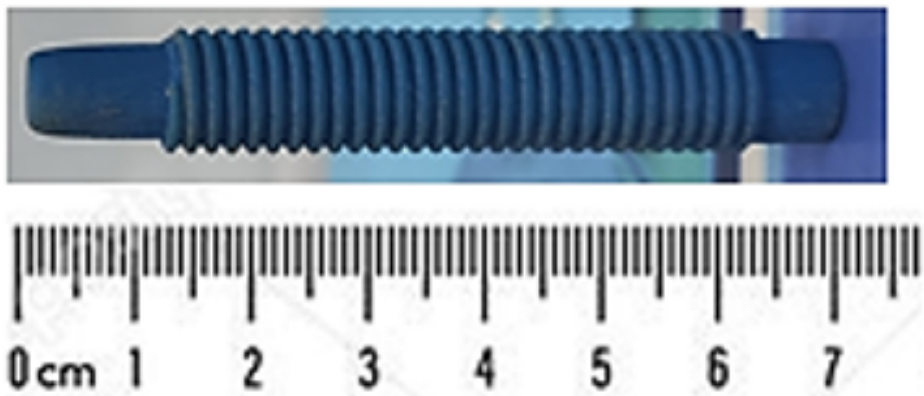

FIGURE 7 (b). The dimension of 3D printed M8 Vero cyan bolt

\section{Figure 7}

See image above for figure legend. 

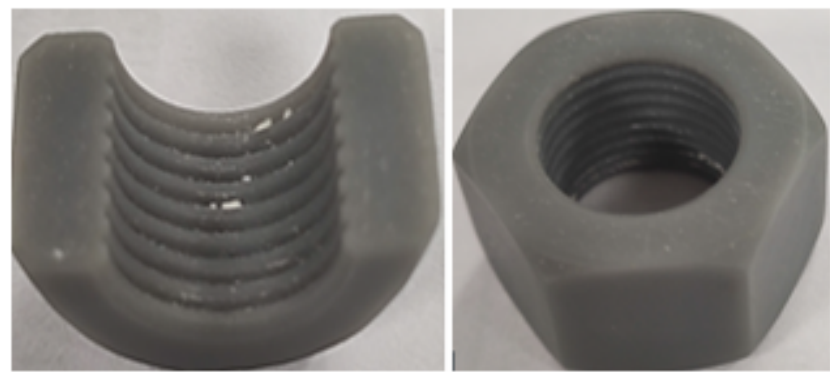

FIGURE 8 (a). M8 Vero grey half 3D printed M8 nut as well as a $3 \mathrm{D}$ printed nut,

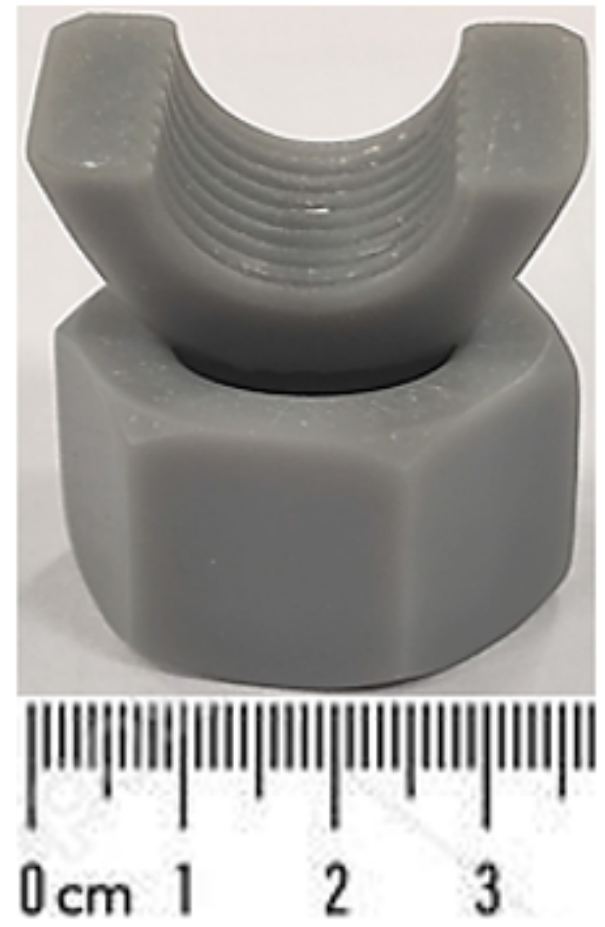

FIGURE 8 (b). 3D printed M8 nut and a falf 3D printed nut illustrating the intemal threads.

\section{Figure 8}

See image above for figure legend. 


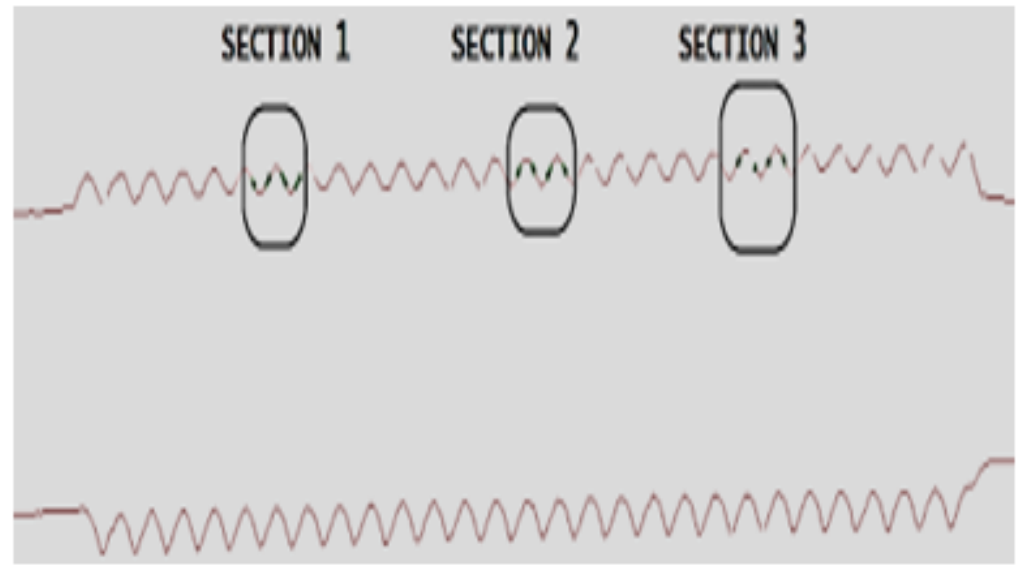

Figure 9

Three randomly selected measurement sections taken on the periphery of the bolt. 

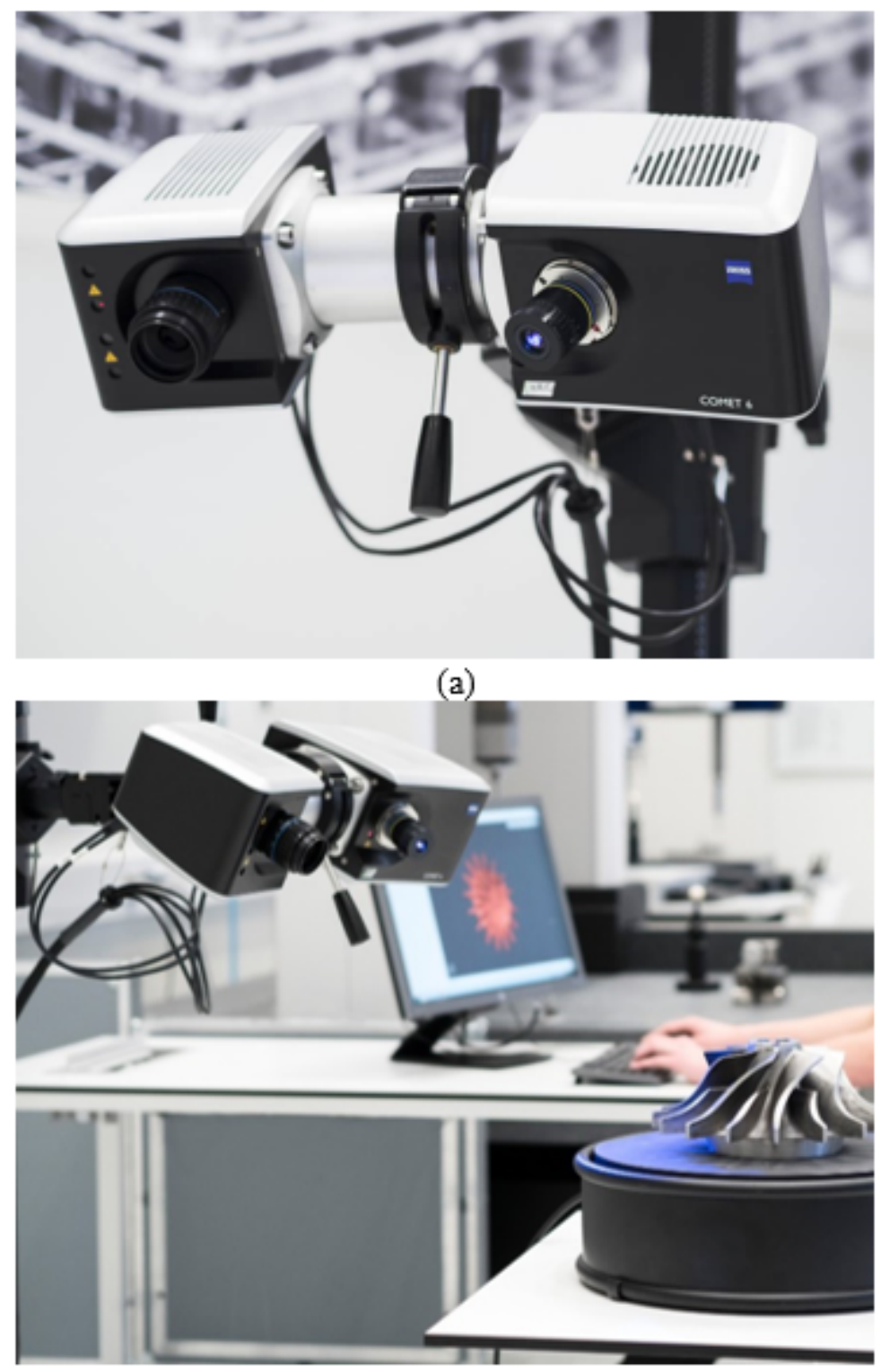

(b)

Figure 10

Carl Zeiss COMET L3D2 3D scanner (a) Scanner emitting blue light (b) Scanner with rotary stand. [39] 


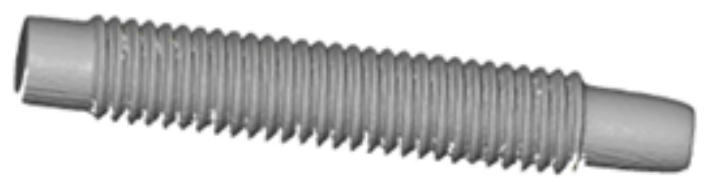

(a)

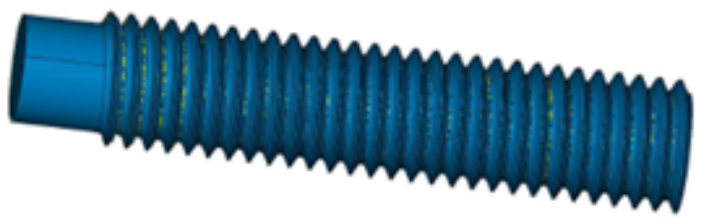

(b)

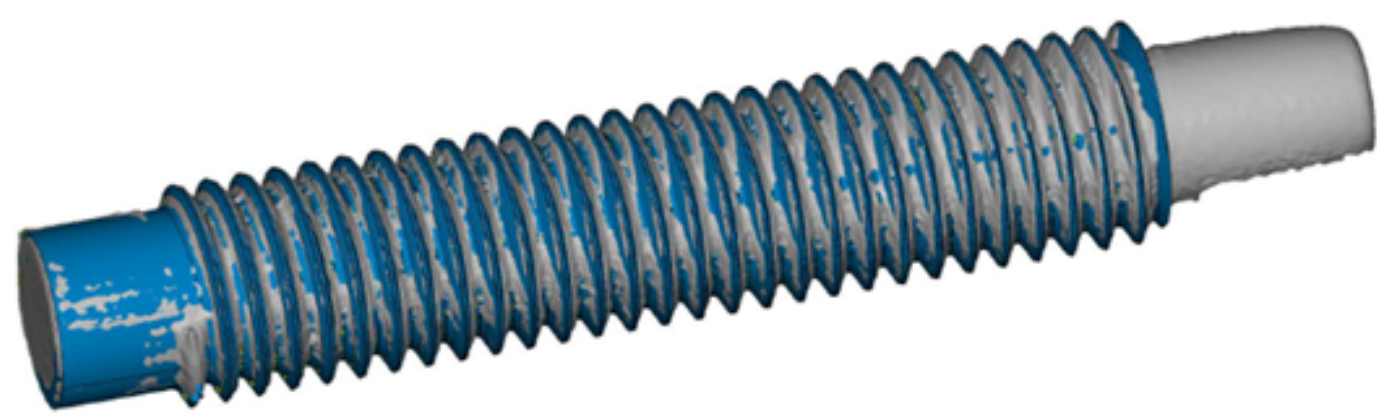

(c)

\section{Figure 11}

(a) M8 bolt's CAD model, (b) 3D scanned M8 bolt (c) Superimposing M8 bolt's CAD model with 3D scanned M8 bolt.

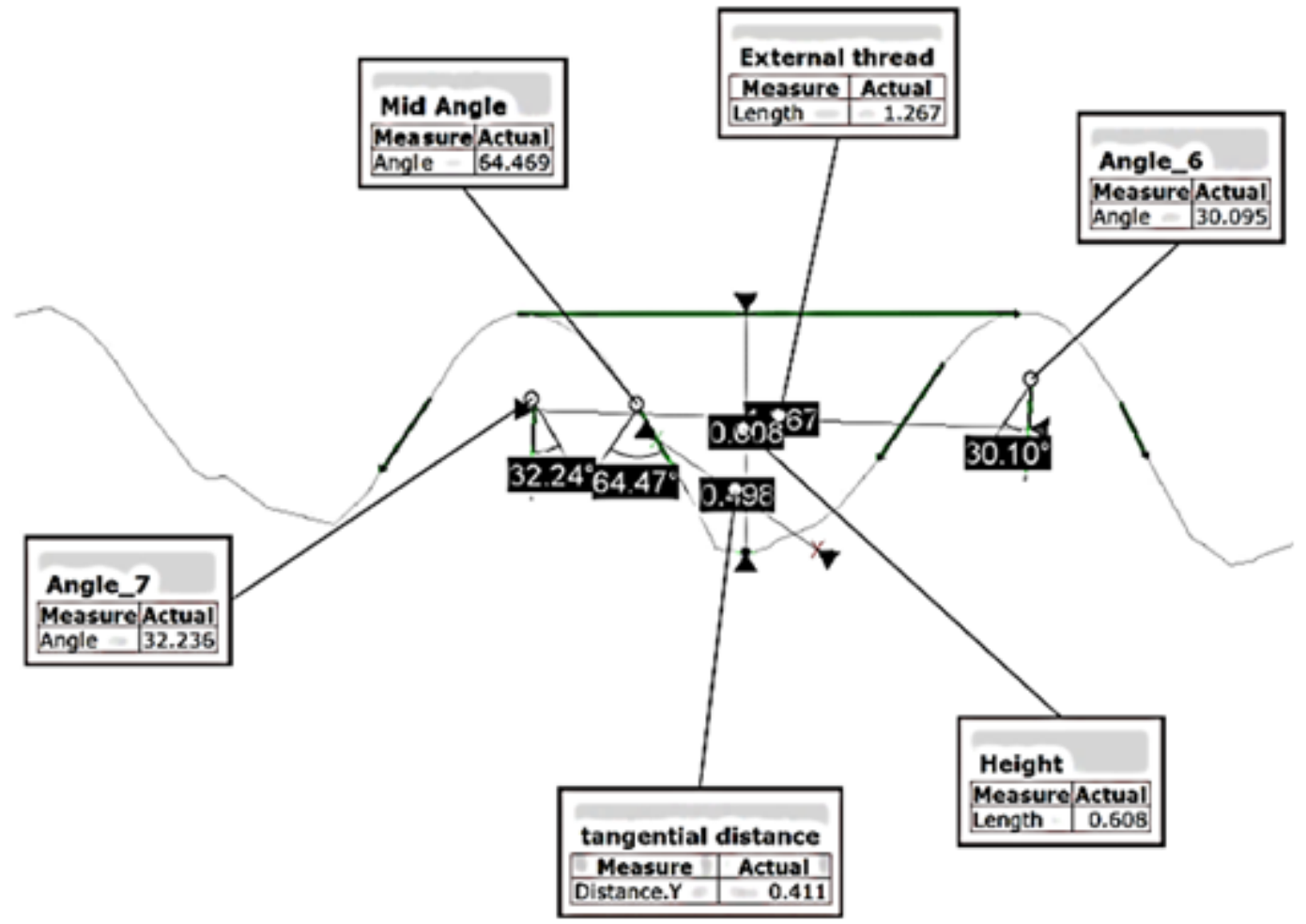

Figure 12

Thread profile of M8 bolt measured by 3D scanner (dimensions in $\mathrm{mm}$, angle in degree). 


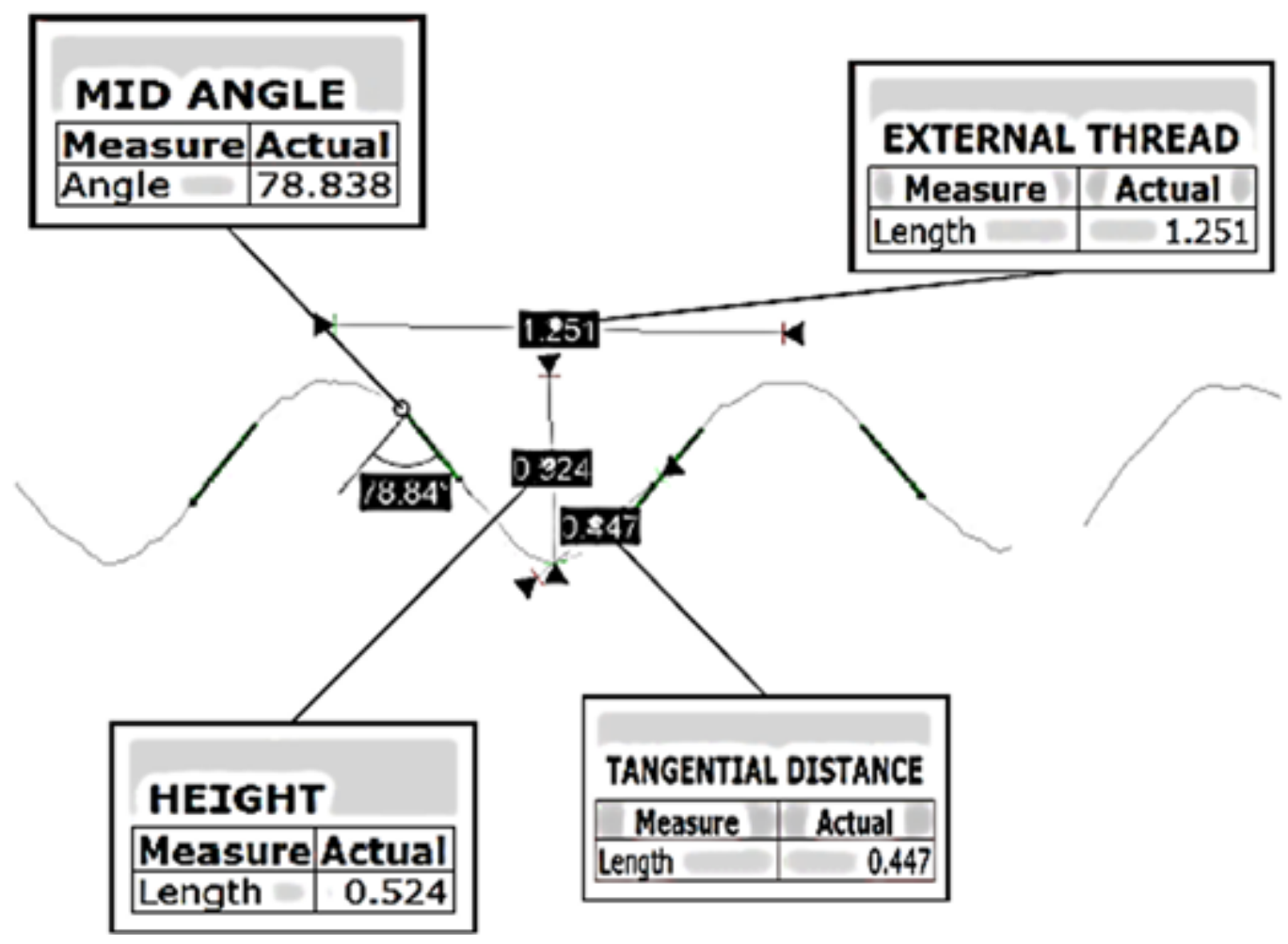

Figure 13

Thread profile of Vero cyan measured by 3D scanner (dimensions in $\mathrm{mm}$, angle in degree).

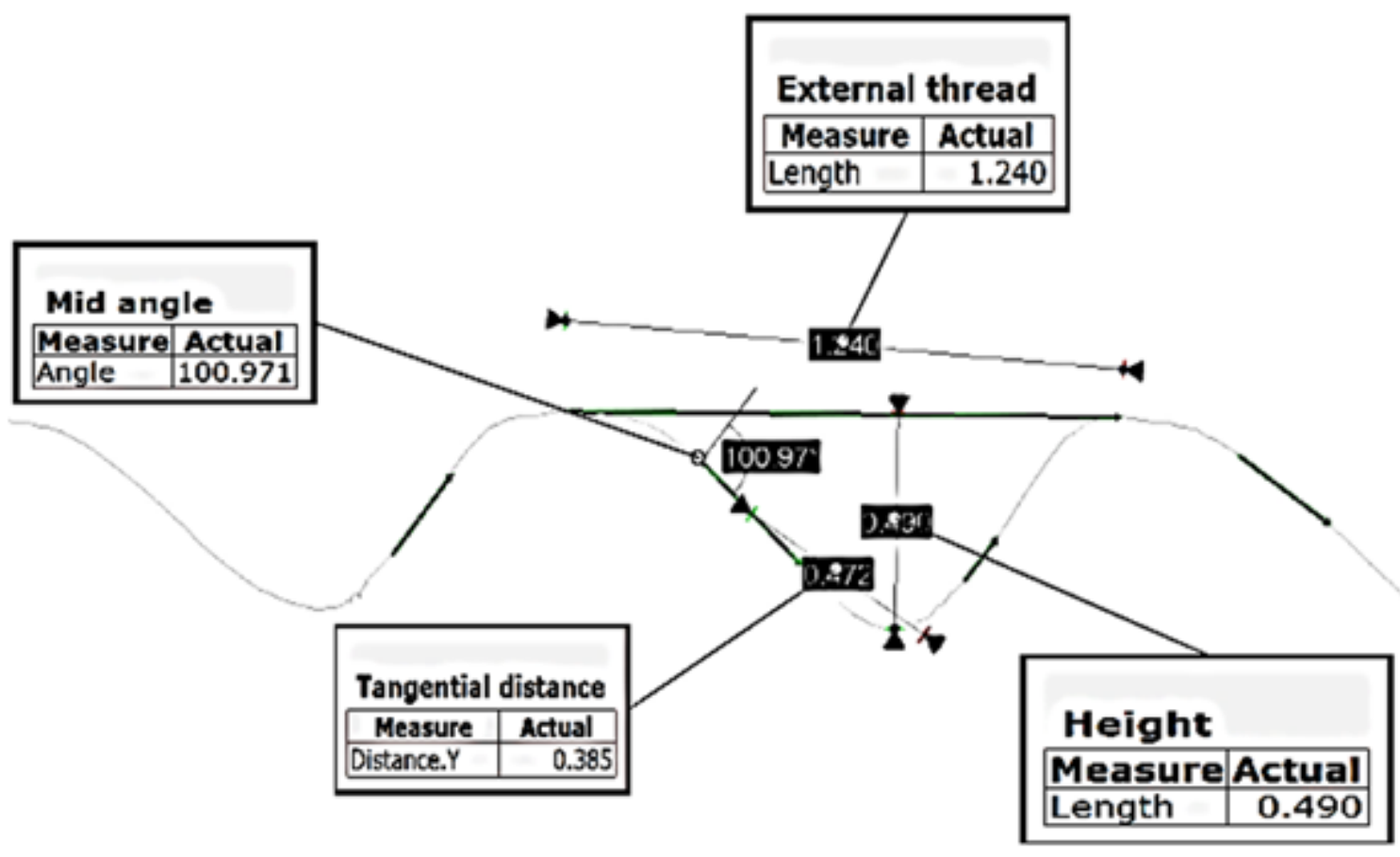

Figure 14

Thread profile of Vero magenta measured by 3D scanner (dimensions in $\mathrm{mm}$, angle in degree). 


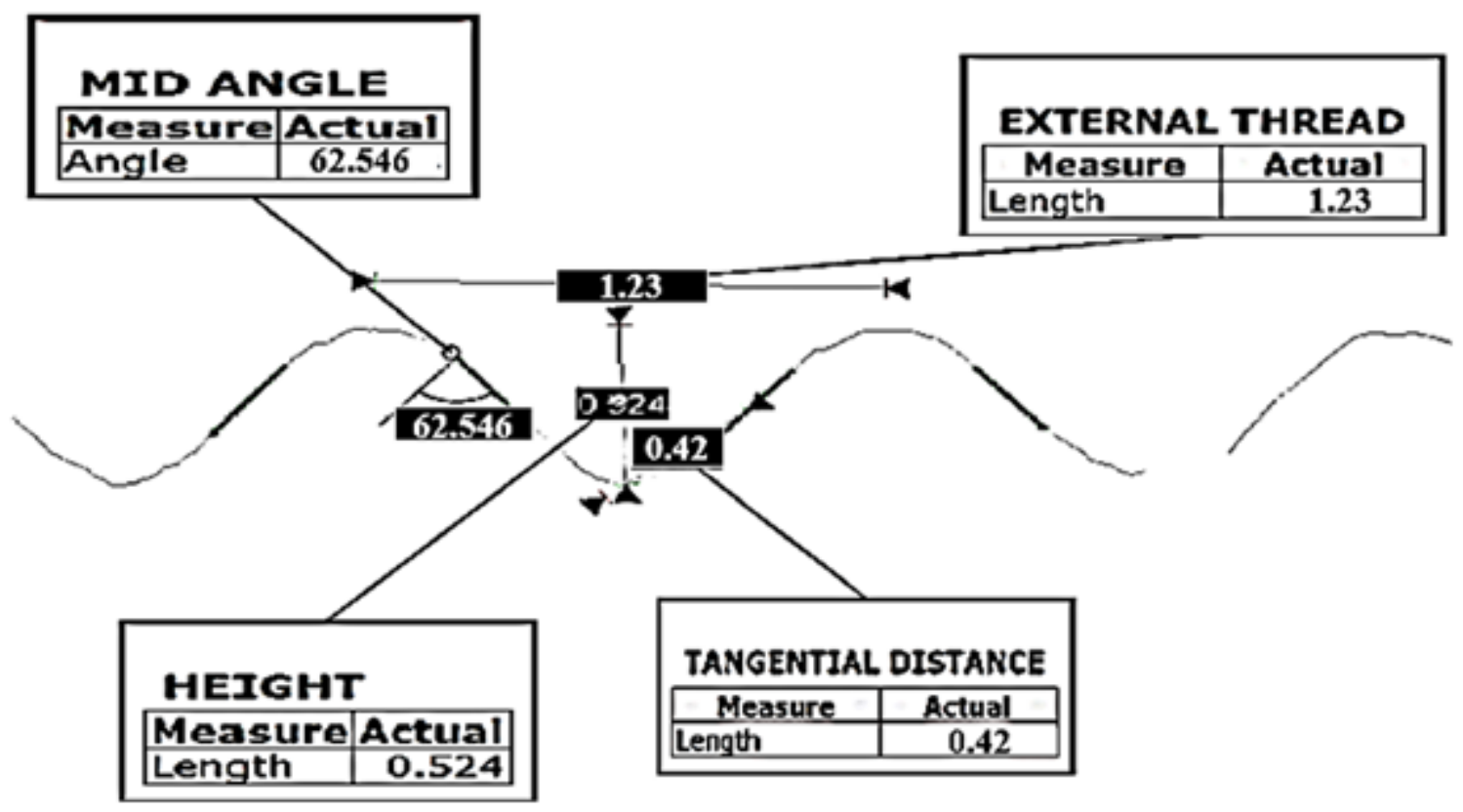

Figure 15

Thread profile of Vero white bolt measured by 3D scanner (dimensions in $\mathrm{mm}$, angle in degree). 


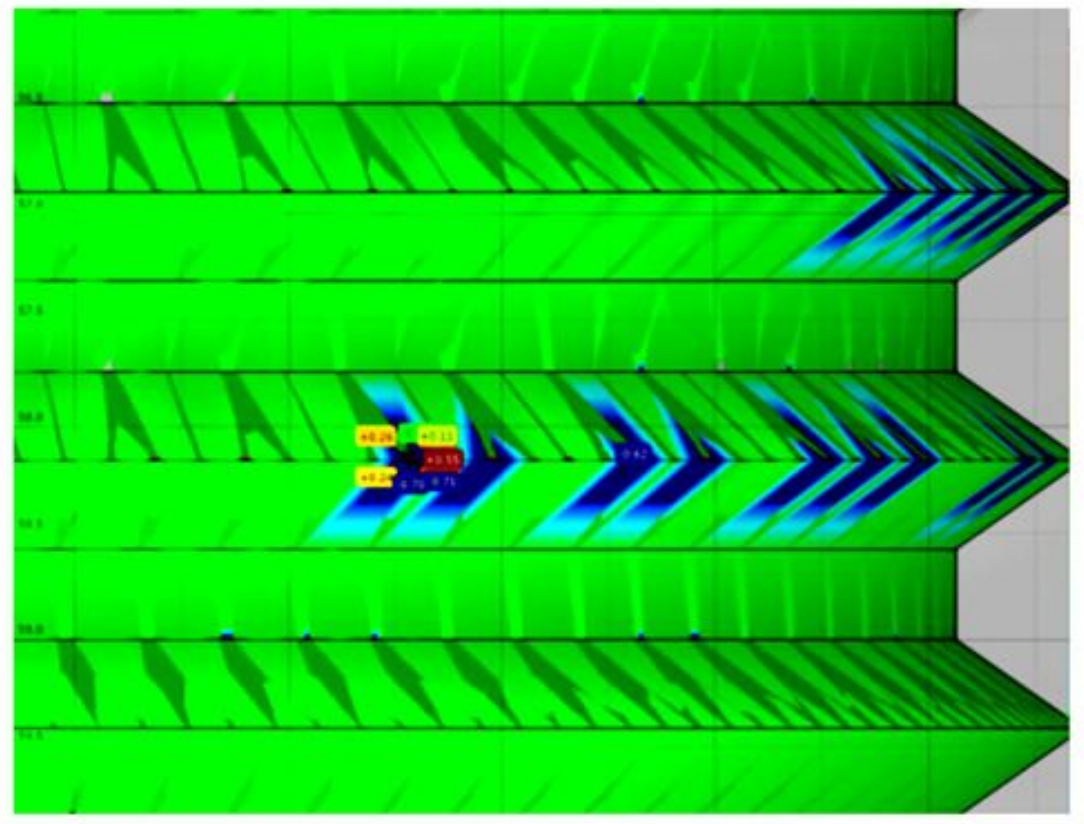

FIGURE 16 (a). Internal thread profile of Vero grey nut measured by 3D scanner (dimensions in mm, angle in degree).

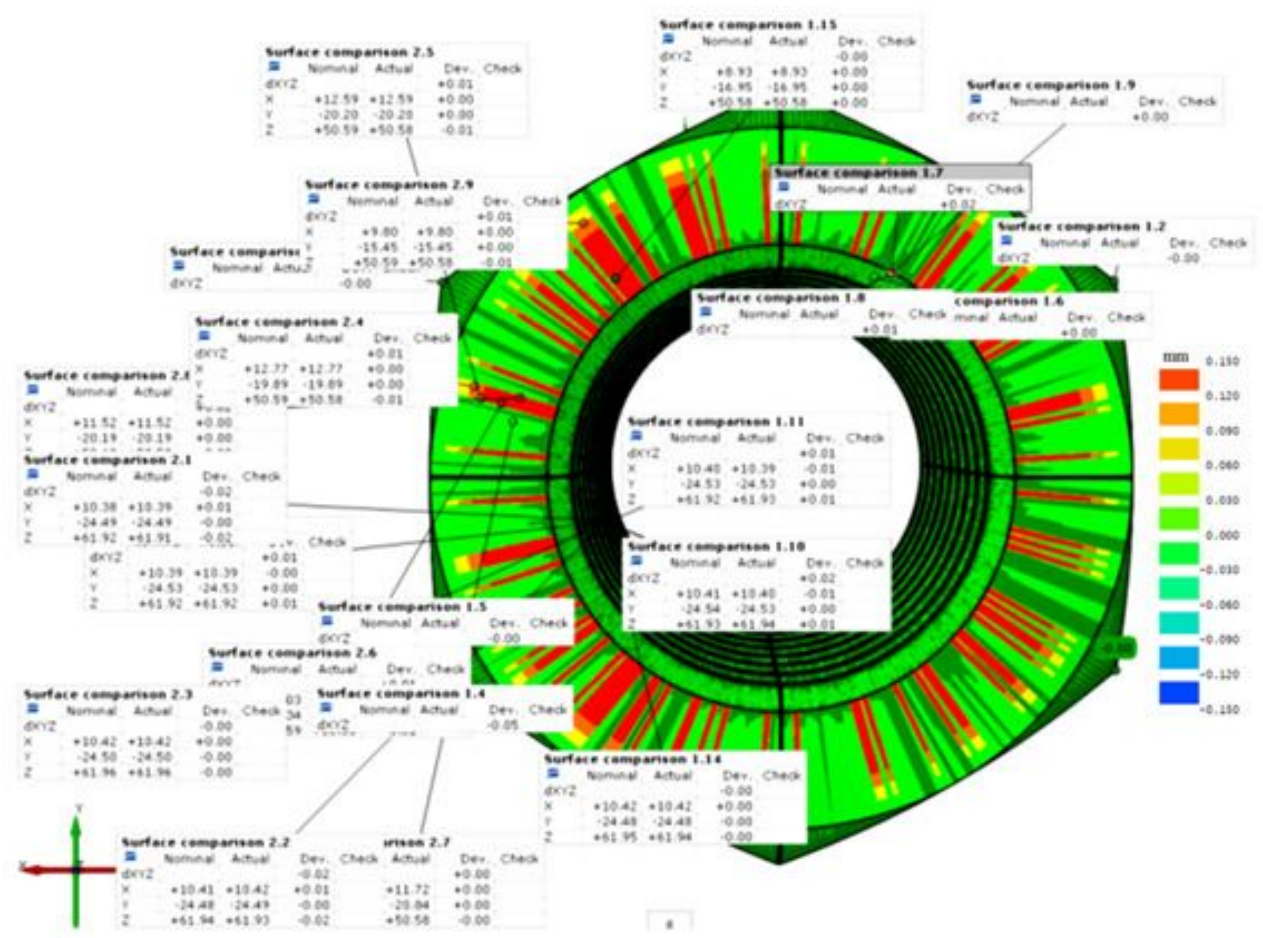

FIGURE 16 (b). Surface features of Vero grey nut measured by 3D scanner (dimensions in mm, angle in degree).

\section{Figure 16}

See image above for figure legend. 


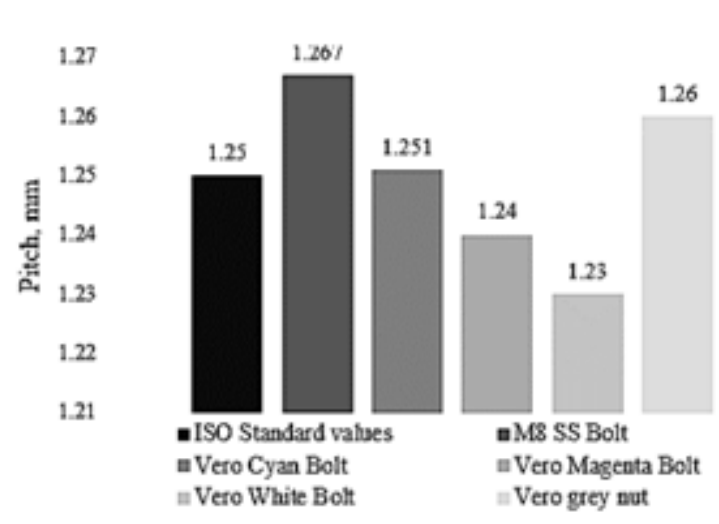

(a)

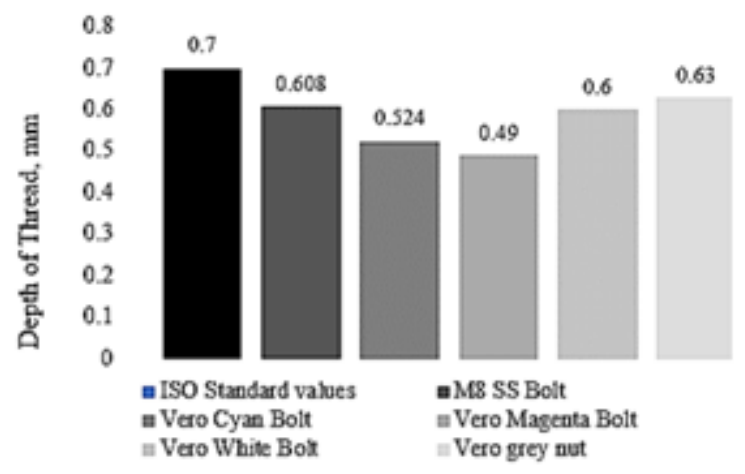

(c)

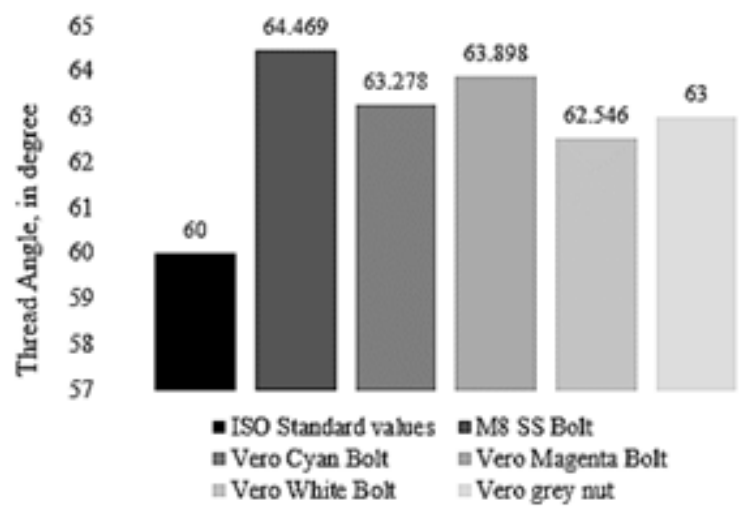

(b)
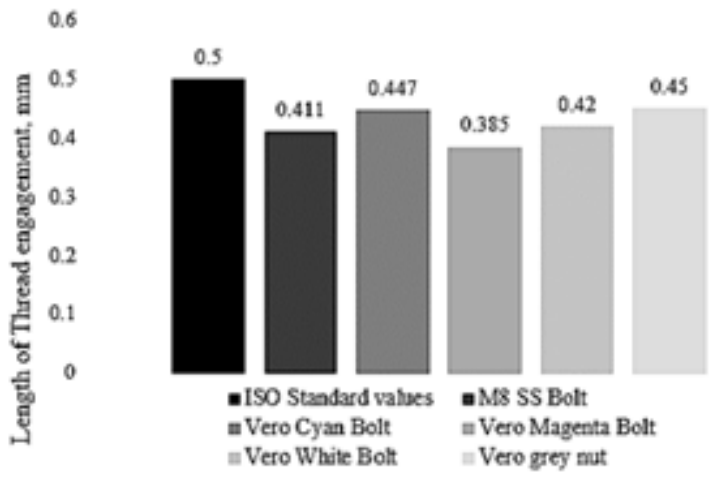

(d)

\section{Figure 17}

Comparison of parameters (a) pitch, (b) thread angle, (c) depth of thread, and (d) length of thread engagement with ISO dimensions in $\mathrm{mm}$ and angle in degrees.

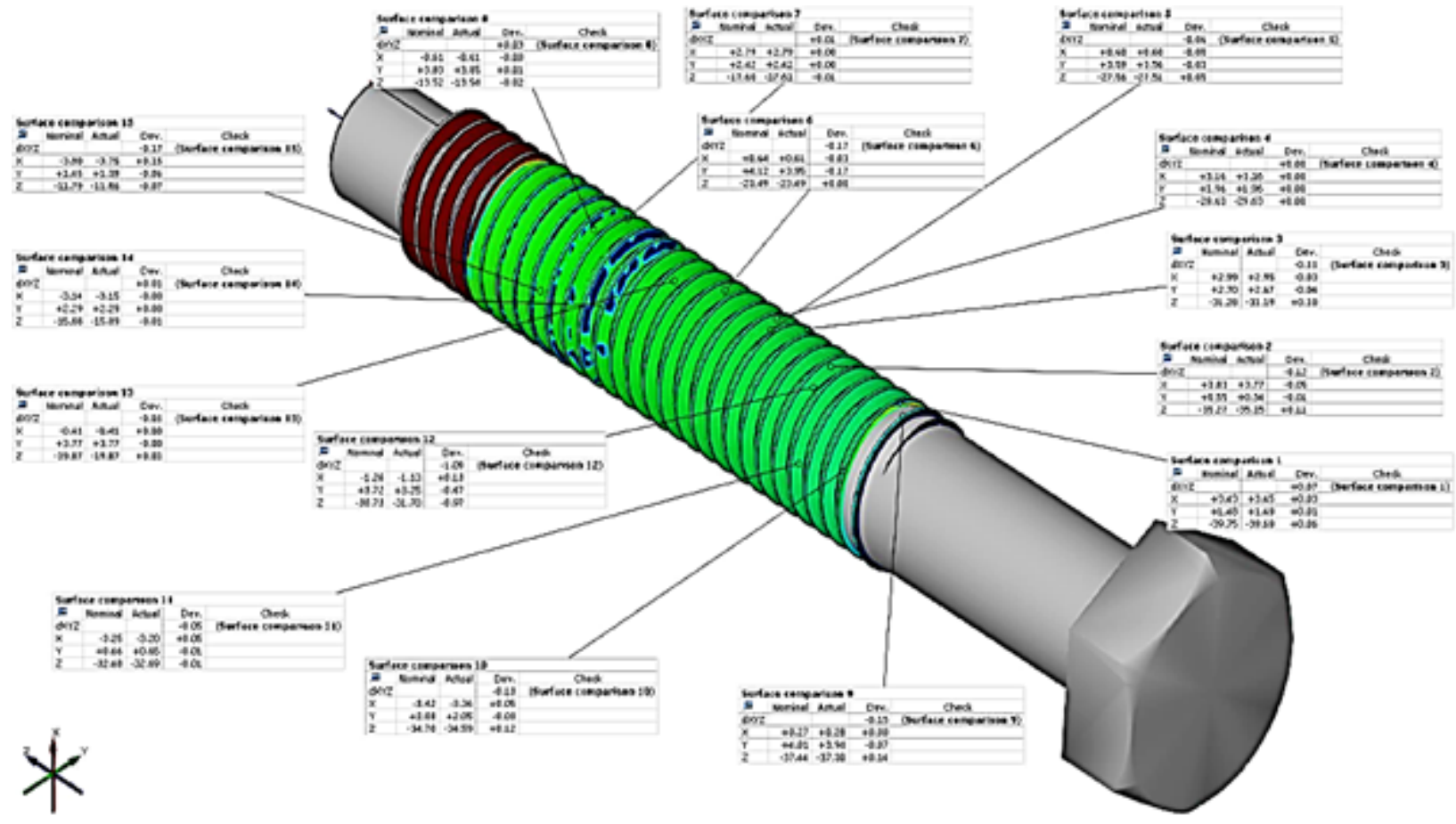


3D Tolerance chart of Vero white superimposed with an ISO Standard M8 bolt, in $\mathrm{mm}$.

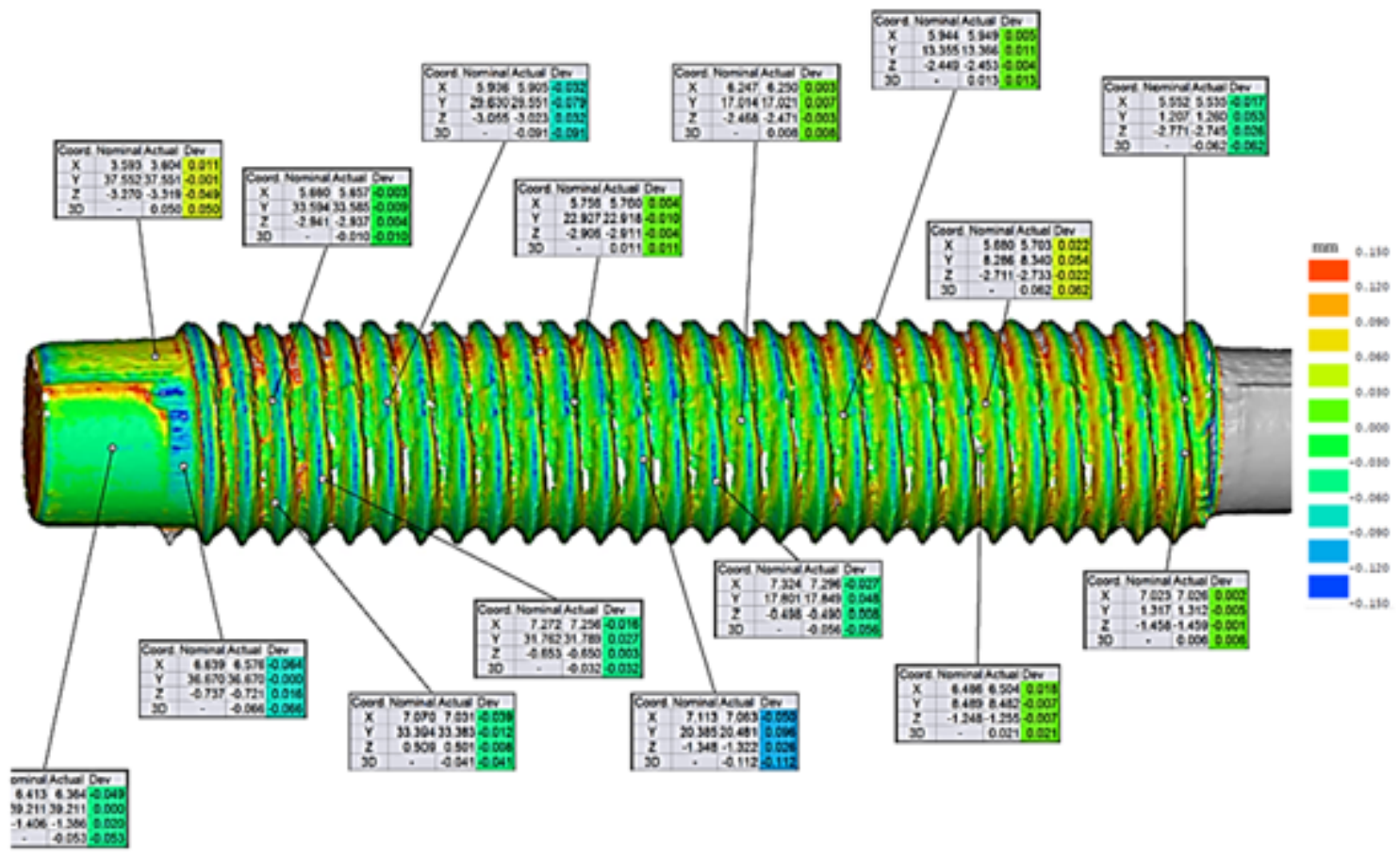

Figure 19

3D Tolerance chart of Vero cyan superimposed with an ISO Standard M8 bolt, in mm.

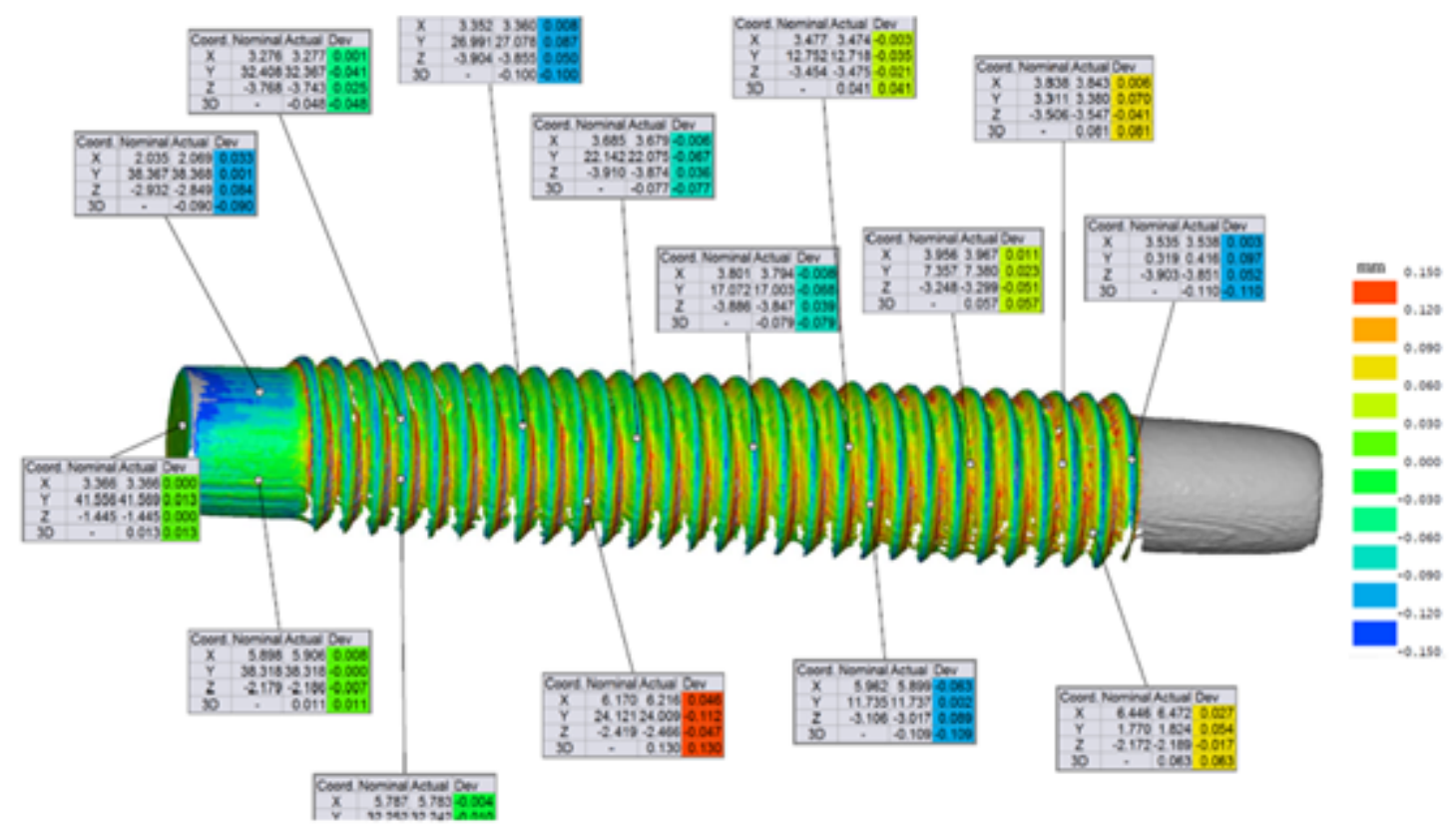

Figure 20

3D Tolerance chart of Vero magenta superimposed with an ISO Standard M8 bolt, in $\mathrm{mm}$. 


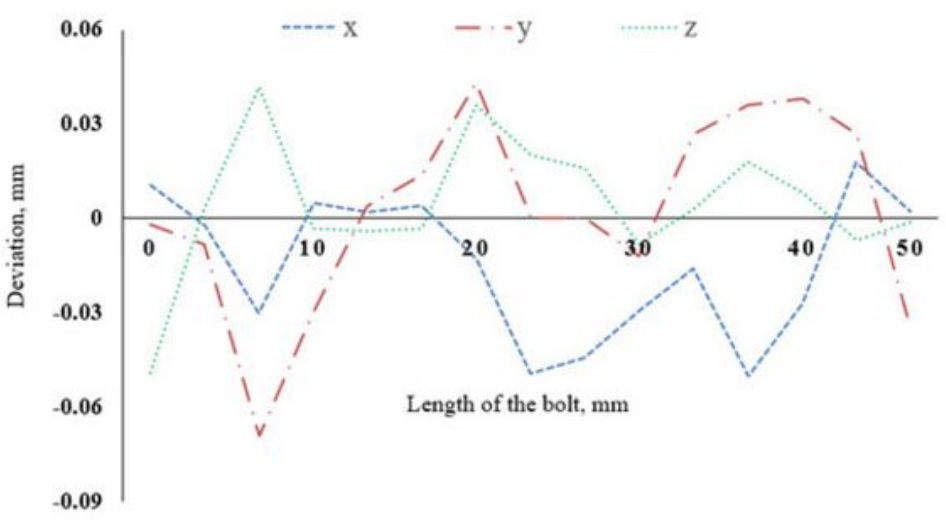

FIGURE 21. (a) Directional Deviation for Vero white bolt

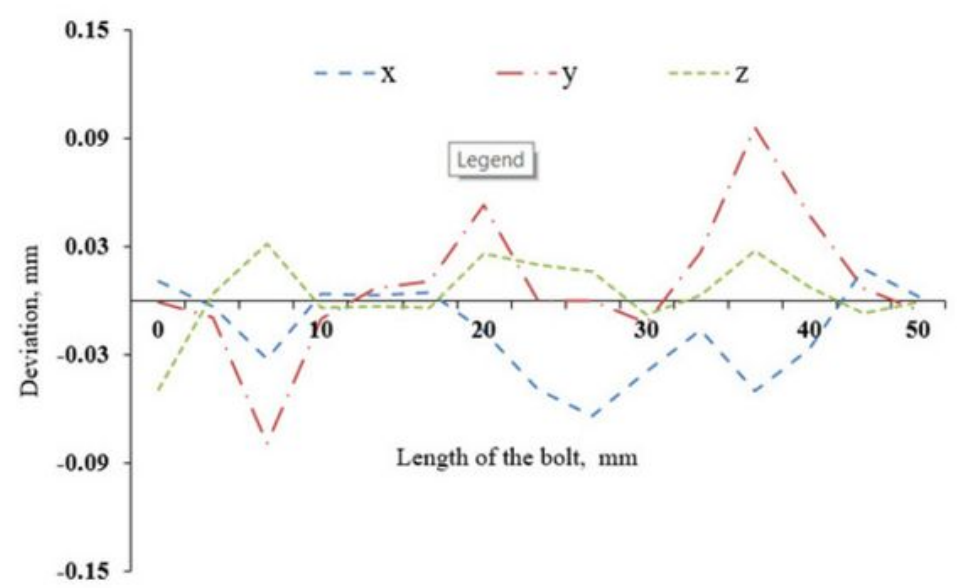

FIGURE 21. (b) Directional Deviation for Vero cyan bolt

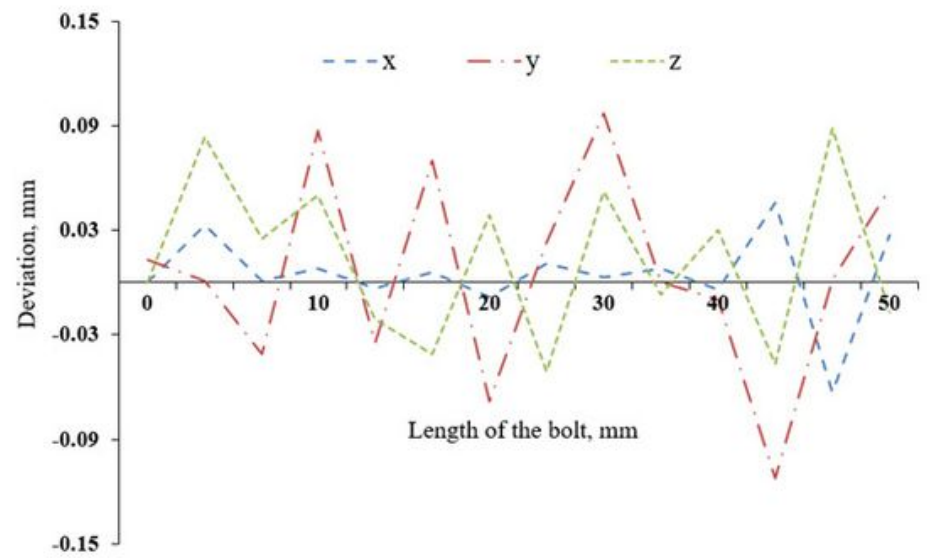

FIGURE 21. (c) Directional Deviation for Vero magenta bolt

\section{Figure 21}

See image above for figure legend. 


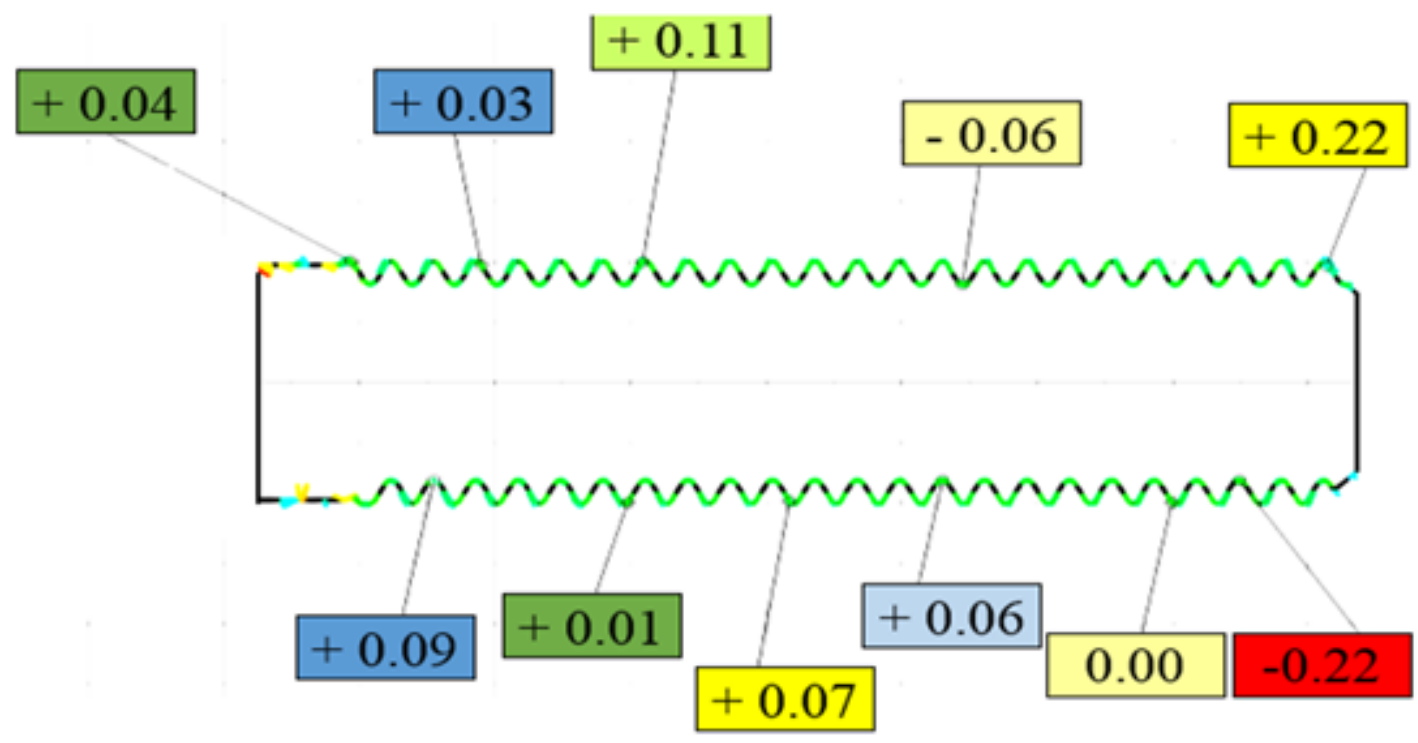

Figure 22

Dimensional deviation of a sectional view of Vero White compared with M8 bolt, in $\mathrm{mm}$.

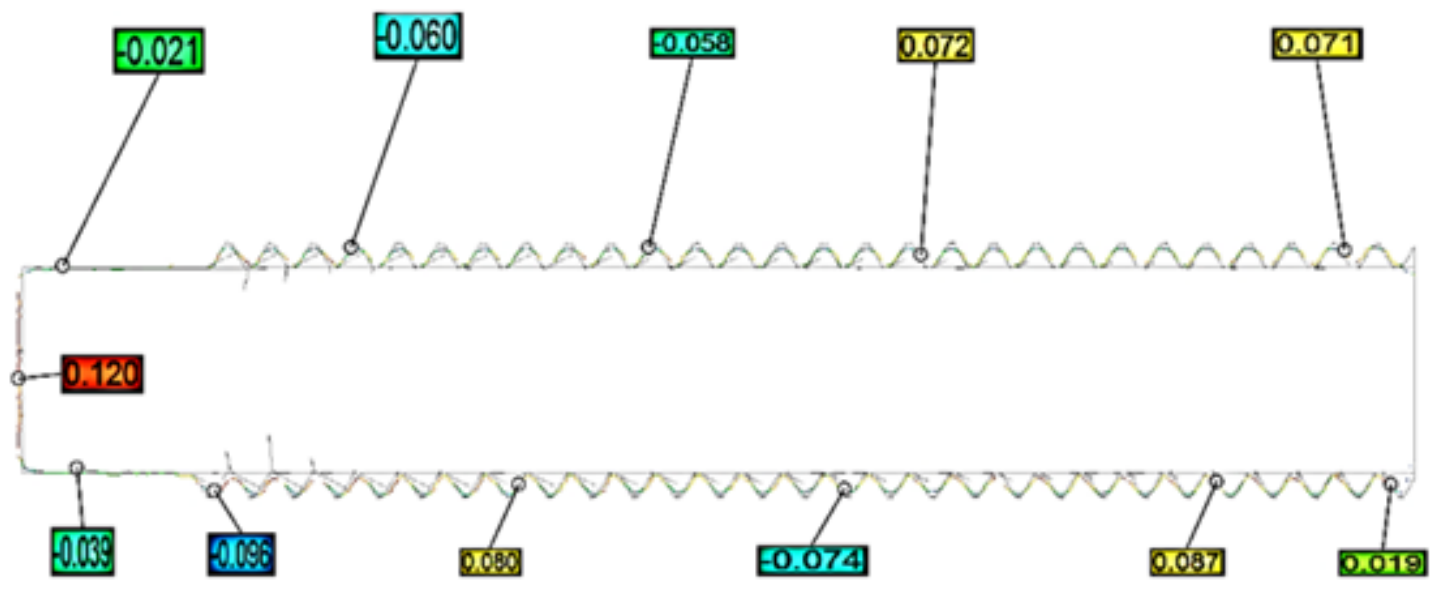

Figure 23

Dimensional deviation of a sectional view of Vero Cyan compared with M8 bolt, in $\mathrm{mm}$.

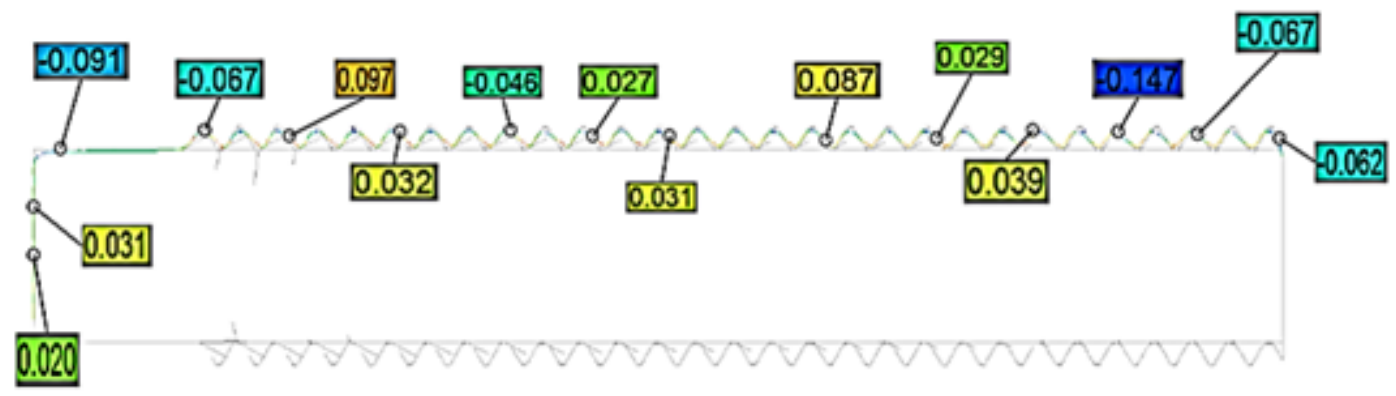


Figure 24

Dimensional deviation of a sectional view of Vero Magenta compared with M8 bolt, in $\mathrm{mm}$.

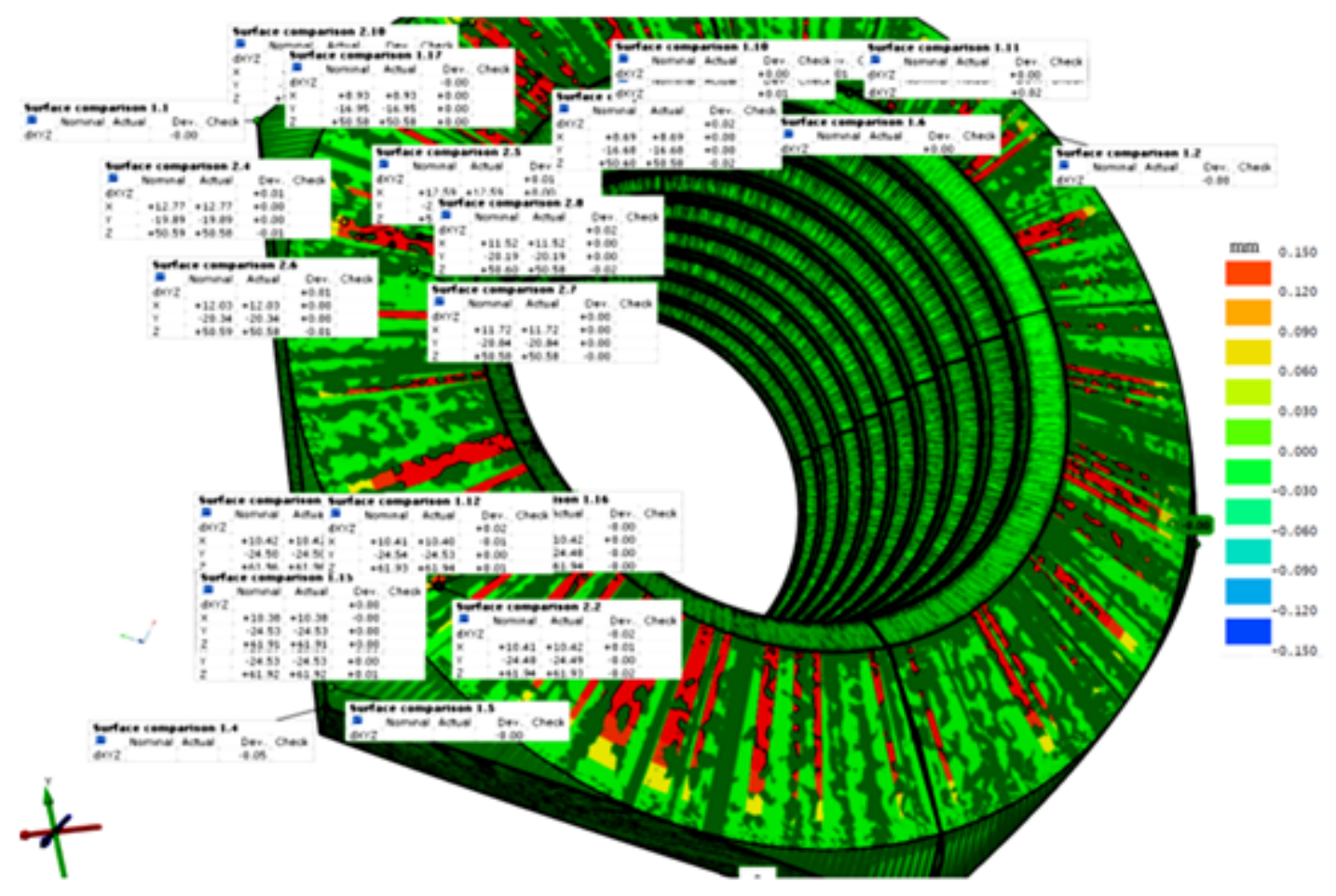

\section{Figure 25}

3D Tolerance chart of Vero grey nut superimposed with an ISO Standard M8 nut, in mm.

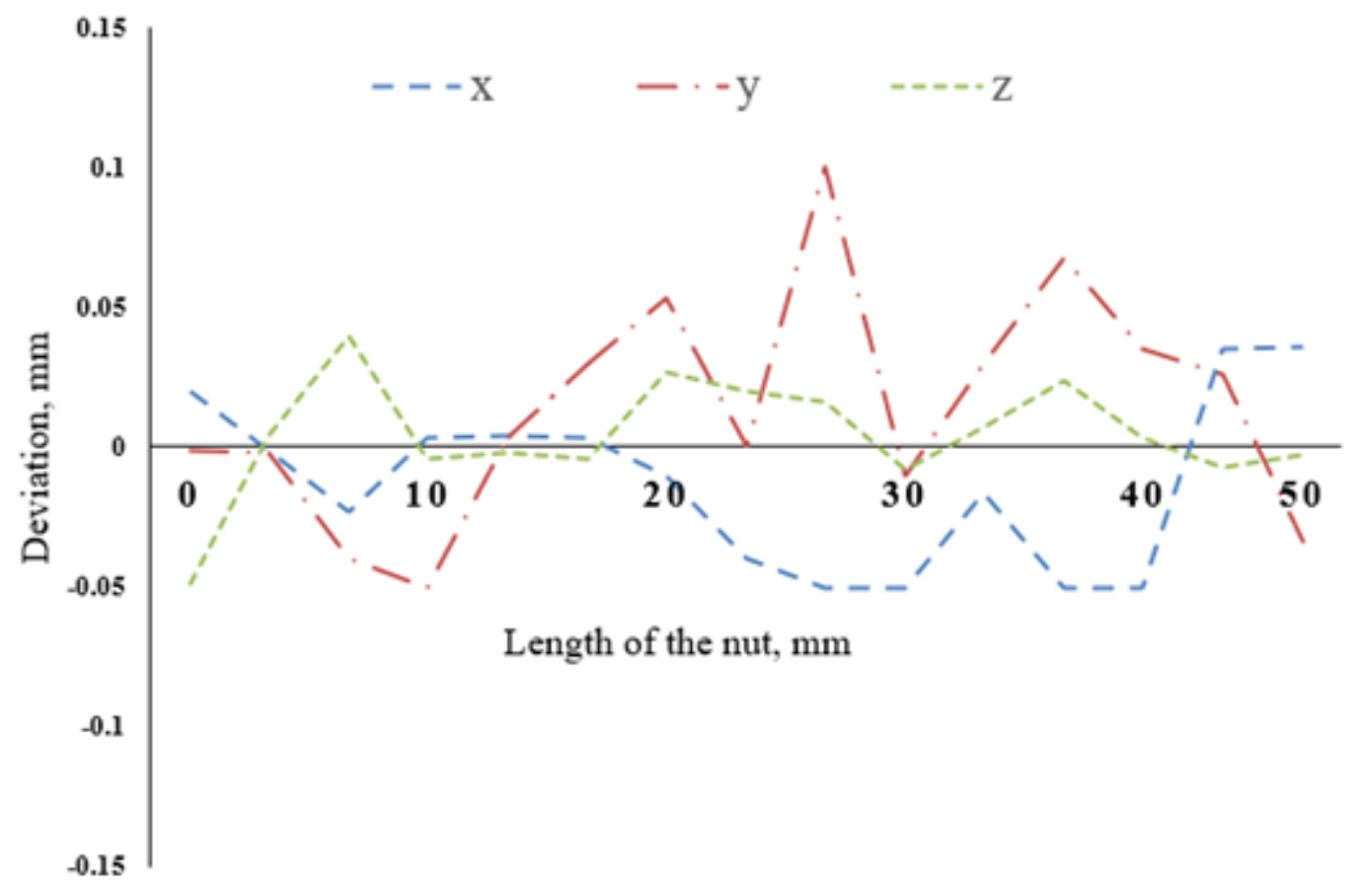


Figure 26

Directional Deviation for Vero grey nut. 